\title{
Asymmetric First-Price Menu Auctions under Intricate Uncertainty
}

\author{
Seungjin Han*
}

March 19, 2013

\begin{abstract}
This paper studies asymmetric first-price menu auctions in the procurement environment where the buyer does not commit to a decision rule and asymmetric sellers have interdependent costs and statistically affiliated signals. Sellers compete in bidding a menu of contracts, where a contract specifies a vector of characteristics and a payment required from the buyer for delivering these characteristics. The buyer does not commit ex-ante to a decision rule but rather upon observing all the menus offered by sellers chooses the best contract. This paper establishes the existence of a continuum of separating monotone equilibria in this game bounded above by the jointly ex-post efficient outcome and below by the jointly interim efficient outcome. It shows that the jointly ex-post efficient equilibrium outcome is the only ex-post renegotiation proof outcome and it is also ex-ante robust to all continuation equilibria.
\end{abstract}

\section{Introduction}

Procurement of goods or services is an important part of the economy. For example, public procurement by governments accounts for 10 to $15 \%$ of GDP in developed countries and up to $20 \%$ of GDP in developing countries. The items acquired through procurement vary from simple stationary items to highly complex goods and services such as infrastructure projects, nuclear power plants, and military weapons. In order to model procurement, various scoring auctions where a buyer (e.g., government) can commit to a scoring rule are proposed in the

*I am very grateful to the Associate Editor, an anonymous referee, and René Kirkegaard for their comments and suggestions. All errors are mine alone. Address: Department of Economics, McMaster University, 1280 Main Street West, Hamilton, Ontario, Canada L8S 4M4. Email: hansj@mcmaster.ca. 
literature. In scoring auctions, each seller submits a single bid (or equivalently a single contract), i.e., a vector of characteristics of the good and a payment required from the buyer for delivering these characteristics. ${ }^{1}$ The scoring rule calculates each seller's score given his bid and the seller with highest score wins procurement. ${ }^{2}$ Examples of scoring auctions include the first scoring auction, the second scoring auction, and the handicap auction. ${ }^{3}$

While scoring auctions generate competitive bidding in an intuitive way, scoring rules must specify scores for all possible bids that sellers may submit. This may be quite complex, especially when characteristics of the good are highly multidimensional. For example, when a government is considering awarding a contract for the construction of a tunnel in a mountainous area, the specification of the tunnel to be built would be highly multidimensional. The characteristics may include the possible route, length, and radius of the tunnel, the construction method to be utilized, the air ventilation system, the construction time, and the operating issues after the construction: the list of the specifications goes on and on. In this case, it may not be economically viable for the government to commit itself to a scoring rule that specifies a score for every possible bid. The difficulty of procurement of tunnel construction is compounded because the construction cost may not be fully known to the construction companies. The construction cost will depend on the geological characteristics of the mountain, the composition and distribution of minerals in the area in which the tunnel is to be constructed. Different construction companies may receive different signals on construction costs. Those signals have interdependent values in the sense that each company's estimate of its construction cost depends on all companies' signals and its estimate would be more precise if other companies' signals were known to the company.

This paper analyzes procurement in the environment where the buyer does not commit ex-ante to a decision rule and asymmetric sellers have interdependent costs and statistically affiliated signals. With no ex-ante commitment to a scoring rule, a buyer (e.g., government) may, in practice, simply advertise open invitations for the procurement of a highly complex good or service with a few descriptive objectives. Sellers can then submit and present their proposals, which often include multiple possible bids, i.e., pairs of characteristics of the good and

\footnotetext{
${ }^{1}$ Che (1993) and Asker and Cantillon (2008) study scoring auctions in situations where sellers' signals on production costs have only private values. Branco (1997) considers scoring auctions with symmetric sellers, independent signals and common values.

${ }^{2}$ We use feminine pronouns for the buyer and masculine pronouns for sellers.

${ }^{3}$ Given the scoring rule in each auction, the seller with the highest score wins procurement. In the first scoring auction, the winning seller executes the contract he submits. In the second scoring auction, the winning seller can execute any contract that matches the highest rejected score. The handicap auction can give different additional scores to different sellers on top of scores based on the contracts that they submit.
} 
payment. It may take the government a few months or years to evaluate the proposals and start negotiating with the winning seller on the characteristics of the good to be delivered and the corresponding payment. Abstracting from reality, this paper formulates the first-price menu auction in which each seller bids a menu of contracts and, upon observing all the menus offered by sellers, the buyer chooses the best contract.

This type of menu auctions is relevant and interesting for procurement particularly under interdependent values. Let $u(x)-t$ be the buyer's payoff, where $x$ is a vector of characteristics of the good delivered to him and $t$ is a payment from him. For the private value case, let $t-c_{i}\left(x, s_{i}\right)$ be the payoff for seller $i$ with signal $s_{i}$ on production costs, where $c_{i}\left(x, s_{i}\right)$ denotes the production cost of $x$. In the private value case, the joint ex-post efficient vector of characteristics of the good, $x_{i}^{*}\left(s_{i}\right) \in \arg \max _{x}\left\{u(x)-c_{i}\left(x, s_{i}\right)\right\}$, delivered by seller $i$ depends only on his signal $s_{i}$. Even without the buyer's commitment for a scoring rule, seller $i$ will always submit the jointly ex-post efficient contract $(x, t)=\left(x_{i}^{*}\left(s_{i}\right), u\left(x_{i}^{*}\left(s_{i}\right)\right)-\tilde{u}\right)$ when his signal is $s_{i}$ and he is willing to give the payoff level, $\tilde{u}$ to the buyer. This is because $(x, t)=\left(x_{i}^{*}\left(s_{i}\right), u\left(x_{i}^{*}\left(s_{i}\right)\right)-\tilde{u}\right)$ is the contract that maximizes the payoff for seller $i$ with signal $s_{i}$ conditional on winning the procurement given the payoff level, $\tilde{u}$ that she is willing to give to the buyer. Furthermore, it is weakly dominant for a seller to submit a single jointly ex-post efficient contract even when he can submit a menu of contracts.

In the interdependent value case, this is not true anymore. For interdependent values, let $t-c_{i}\left(x, s_{-i}, s_{i}\right)$ be seller $i$ 's payoff, where $s_{-i}$ is a vector of the other sellers' signals and $s_{i}$ is seller $i$ 's signal. The jointly ex-post efficient vector of characteristics $x_{i}^{*}(s) \in \arg \max _{x}\left\{u(x)-c_{i}(x, s)\right\}$ depends on all sellers' signals $s=$ $\left(s_{-i}, s_{i}\right)$. If sellers can offer menus of contracts, seller $i$ with signal $s_{i}$ can include every possible jointly ex-post efficient contract $(x, t)=\left(x_{i}^{*}\left(s_{-i}, s_{i}\right), u\left(x_{i}^{*}\left(s_{-i}, s_{i}\right)\right)-\right.$ $\tilde{u})$ in his menu for every possible $s_{-i}$ given the payoff level, $\tilde{u}$ that he is willing to give to the buyer. If each seller makes his menu offer contingent on his signal, then the buyer will learn about all sellers' signals by observing their menus. Given her correct perception on all sellers' signals, the buyer can then choose the jointly expost efficient contract $\left(x_{i}^{*}\left(s_{-i}, s_{i}\right), u\left(x_{i}^{*}\left(s_{-i}, s_{i}\right)\right)-\tilde{u}\right)$ at each $s_{-i}$ upon accepting the menu offered by seller $i$ with signal $s_{i}$.

However, when the menu includes multiple contracts that all generates the same payoff for the buyer, the buyer can choose any contract from the menu and hence the contract that the buyer chooses may not be necessarily jointly ex-post efficient. A seller's equilibrium menu offer therefore depends on his belief on how likely the buyer would choose a contract that would maximize the ex-post joint surplus when it is equally optimal with some of other alternative contracts in the menu. This paper studies a separating monotone equilibrium in which a seller reveals his signal by making his equilibrium menu offer contingent on his signal. Let $\tau_{i}$ denote the probability that the buyer chooses a contract that maximizes 
the ex-post joint surplus in a continuation equilibrium when it is one of the best contracts for her in seller $i$ 's menu. In turn, $1-\tau_{i}$ denotes the probability that the buyer chooses the same contract in seller $i$ 's menu, regardless of her belief on the other sellers' signals, which must be jointly interim efficient in a continuation equilibrium. A vector $\tau=\left[\tau_{1}, \ldots, \tau_{N}\right] \in[0,1]^{N}$ then denotes sellers' beliefs on how likely the buyer chooses a contract that maximizes the ex-post joint surplus across sellers' menus.

This paper establishes a continuum of separating monotone equilibria in which lower cost sellers leave weakly higher rents to the buyer, for the entire space of sellers' beliefs $[0,1]^{N}$. Following Reny's existence result (2011), one could establish the existence of a separating monotone equilibrium if each seller's interim payoff function were weakly quasisupermodular and weakly single crossing given the other sellers' non-decreasing strategies. However, a seller's interim payoff functions may fail to be weakly quasisupermodular or weakly single crossing at irrational bids or rational bids with a positive probability of ties just as Athey's single crossing condition may fail in first price auctions with single dimensional bids (Reny and Zamir 2004). ${ }^{4}$ This paper extends Reny and Zamir's "individually rational tieless single crossing condition" (IRT-SCC) and introduces the "tieless supermodular condition" (TLS-SMC). This paper shows that IRT-SCC and TLS-SMC ensure both the weakly single crossing condition and the weakly quasisupermodular condition at individually rational tieless bids, which are sufficient to establish the existence of a separating monotone equilibrium at any given $\tau=\left[\tau_{1}, \ldots, \tau_{N}\right]$. Subsequently the existence of a separating monotone equilibrium is established at any given $\tau=\left[\tau_{1}, \ldots, \tau_{N}\right]$ by showing that IRT-SCC and TLS-SMC are satisfied in our model.

The continuum of separating monotone equilibria is bounded above by the joint ex-post efficiency level and below by the level of joint interim efficiency. Given the continuum of separating monotone equilibria, we examine which equilibrium is stable under two criteria. First of all, we adopt the notion of jointly ex-post renegotiation-proof equilibrium in which it is not mutually beneficial for the buyer and the winning seller to renegotiate their contract given a signal vector. If equilibrium is not jointly ex-post efficient, there is a positive probability that a mutually beneficial renegotiation between the buyer and the winning seller exists. While there is a continuum of equilibria, the jointly ex-post efficient equilibrium is the only one that is jointly ex-post renegotiation-proof.

Joint ex-post renegotiation is a notion that can be used to examine whether

\footnotetext{
${ }^{4}$ Reny and Zamir (2004) show that IRT-SCC is sufficient to show the existence of a monotone equilibrium in first price auctions with single dimensional bids in the general case involving asymmetric bidders, interdependent values, and affiliated signals. The existence of equilibrium in first price auctions can also be found in Athey (2001), Bresky (1999), Jackson and Swinkels (2005), Lebrun (1999), Maskin and Riley (2000a). Those works restrict attention to either two bidders, symmetric bidders, independent signals, and private or common values.
} 
the buyer and the winning seller can improve upon the contract after the winning seller is chosen. Sellers may consider deviations from their menu offers (i.e., change their menus) even before the buyer chooses a winning seller. Given the multiplicity of continuation equilibrium that the buyer chooses to follow for her contract choice, sellers' incentives for deviations depend on the continuation equilibrium that they believe the buyer would choose upon their deviations. For example, consider a separating monotone equilibrium based on a continuation equilibrium in which the buyer always chooses a jointly interim efficient contract from seller 1's menu upon accepting it, but always chooses a jointly ex-post efficient contract from the other sellers' menus. If seller 1 believed that the buyer would in fact follow the continuation equilibrium where she always chooses a jointly ex-post efficient contract from his menu following his deviation, then seller 1 could deviate to a more aggressive menu, which provides a higher payoff to the buyer than his original menu does, in order to win procurement with a higher probability. Not only does such a deviation show that equilibrium menu offers (and consequently equilibrium contracts) in some equilibrium are not ex-ante robust to the possibility that the buyer would follow an alternative continuation equilibrium, but it also indicates that some equilibrium may not provide stable predictions on how likely each seller would win procurement, because seller 1's deviation to a more aggressive menu makes it more likely for seller 1 to win and less likely for other sellers to win.

In this light, we can examine how ex-ante robust an equilibrium is to (sellers' beliefs on) the continuation equilibrium. If the separating monotone equilibrium is based on a continuation equilibrium in which the buyer chooses a jointly expost efficient contract from the winning seller's menu with positive probability, then it is ex-ante robust to a set of continuation equilibria in which the buyer chooses a jointly ex-post efficient contract with a lower probability. Therefore, if the separating monotone equilibrium is based on a continuation equilibrium in which the buyer chooses a jointly ex-post efficient contract with probability one, then it is ex-ante robust to all continuation equilibria: no sellers have incentives to deviate regardless of the continuation equilibrium that they believe the buyer would choose to follow for her contract choice following their deviations.

Our paper also shows the role of the buyer as an information collector in the interdependent value case. In practice of the first-price menu auction, each seller may submit a lengthy proposal that includes many different aspects of procurement and many possible potential contracts. Furthermore it may be a time-consuming process for the buyer (e.g., government) to review and evaluate sellers' proposals. By reviewing and evaluating sellers' proposals, the buyer develops an accurate idea about their signals on production costs in equilibrium. Therefore, the buyer can act as an information collector in the first-price menu auction. As an information collector, it is practically important for the buyer to establish a reputation that the acquired information on all sellers' produc- 
tion costs would be used when negotiating a contract with the winning seller. It suggests sensitive roles for regulations (e.g., Federal Acquisition Regulation in the U.S.) or oversight agencies (e.g., Office of the Procurement Ombudsman in Canada). Even when the government may not commit to mechanisms or scoring rules, it can establish regulations or oversight agencies for well-defined procedures of the first-price menu auction. They are important not only in preventing favoritism or corruption, and ensuring competitive bidding, but also in providing and maintaining the government's reputation that its additional information on production costs would be used when negotiating a contract with the winning seller. This makes potential sellers submit their proposals, expecting the jointly ex-post efficient equilibrium.

The result also gives us new insight into why multiple open bidding is important in practice especially under interdependent values. Recently, Canada announced a $\$ 9$ billion plan to purchase sixty five F-35 fighter jets from Lockheed Martin. It was heavily criticized because the federal government chose F-35 fighter jets through exclusive bargaining with Lockheed Martin without competitive bidding from other potential sellers. The potential cost of such an exclusive bargaining goes much deeper. The announced plan includes not only the simple purchase of the fighter jets but also the modification of the jets, long-term maintenance, and training that are tailored specific to the needs of Canadian Air Force. The costs of modification, long-term maintenance, and training may not be fully known to the buyer or a single seller. As the buyer invites proposals from many potential sellers and evaluates the proposals, she learns about costs that are not necessarily known to the winning seller. Subsequently, the buyer can negotiate with the winning seller with the knowledge acquired from other sellers' proposals. The federal government of Canada missed such a valuable opportunity by exclusively bargaining with Lockheed Martin. In this light, this paper can also be viewed as offering a new aspect of competitive bidding under interdependent values, in the sense that as the buyer reviews and evaluates sellers' proposals, she learns more about production costs and can use this knowledge during negotiation with the winning seller.

\section{Preliminaries}

The buyer contracts with one of $N$ sellers on the characteristics of the good to be provided and on the monetary payment to be given the seller. Let $\mathcal{N}=$ $\{1, \ldots, N\}$ be the set of sellers. Let $t \in \mathbb{R}$ denote an amount of monetary payment from the buyer to a seller. Let $x \in \mathbb{X}$ denote the characteristics of the good. For any $x, x^{\prime}$ in $\mathbb{X}$, let $x \vee x^{\prime}$ denote the least upper bound (join) of $x$ and $x^{\prime}$, and $x \wedge x^{\prime}$ denote the greatest lower bound (meet) of $x$ and $x^{\prime}$. If $\mathbb{X} \subseteq \mathbb{R}^{n}$, then the join of $x$ and $x^{\prime}$ is the component-wise maximum and the meet is the component-wise 
minimum. A set $\mathbb{X}$ is a lattice if for any $x$ and $x^{\prime}$ in $\mathbb{X}$, the joint and meet of $x$ and $x^{\prime}$ exist as elements of $\mathbb{X}$.

Assumption 1. $\mathbb{X}$ is a compact metric space and a partially ordered lattice with a transitive, reflexive and antisymmetric order relation $\geq{ }^{5}$

Each seller $i$ receives a private signal $s_{i} \in[0,1]$ on the production costs of the good. Throughout the paper, the upper case letter $S_{i}$ will denote seller $i$ 's signal as a random variable and the lower case letter $s_{i}$ will denote its realization. The joint density of sellers' signals is denoted by $f:[0,1]^{N} \rightarrow \mathbb{R}_{+}$. When the buyer and seller $i$ agree to execute a contract $(x, t)$ given a vector of signals $s=\left[s_{1}, \ldots, s_{N}\right]$, seller $i$ 's payoff function is $t-c_{i}(x, s)$, the buyer's payoff function is $u(x)-t$, and the remaining sellers receive their reservation payoffs. If the buyer does not contract with any seller, the buyer and all sellers receive their reservation payoffs. All reservation payoffs are normalized to zero. Note that the payoff of the seller who contracts with the buyer depends on the other sellers' signals, so signals have interdependent values.

Let $R_{i}(x, s)=u(x)-c_{i}(x, s)$ be the joint ex-post surplus between seller $i$ and the buyer when seller $i$ sells the good with characteristics $x$ to the buyer, given a signal vector $s$. For each $s$, let

$$
X_{i}^{*}(s) \equiv \arg \max _{x \in \mathbb{X}} R_{i}(x, s)
$$

be the set of jointly ex-post efficient characteristics of the good. Let $x_{i}^{*}(s)$ denote a typical element in $X_{i}^{*}(s)$. The following explains how a seller's preferences over contracts depend upon the vector of signals.

Consider an example with two sellers and a one dimensional $X$ as in figure 1 . Suppose that seller 1 with signal $s_{1}$ is willing to give the buyer a payoff level $u_{1}$. In figure 1, the lower curve is the buyer's indifference curve associated with the utility level $u_{1}$ and the two curves above it represent the iso-profit curves for seller 1 with the signal $s_{1}$; one with seller 2's signal $s_{2}$ and the other with seller 2's signal $s_{2}^{\prime}$. This shows why conventional scoring auctions (Che 1993) do not induce jointly ex-post efficient procurement under interdependent values. In scoring auctions, each seller submits only one contract $(x, t)$ and the seller wins procurement if the score of his contract is the highest among all contracts submitted by sellers. In the first-price scoring auction, the winning seller's submitted contract becomes the final contract. In the second-preferred-offer auction, the winner has to match the exact characteristics of the good in the highest losing contract. In both scoring auctions, the joint ex-post efficiency is not ensured because the jointly ex-post

\footnotetext{
${ }^{5}$ An order relation is reflexive if $x \geq x$ for all $x \in \mathbb{X}$ and antisymmetric if $x \geq x^{\prime}$ and $x^{\prime} \geq x$ implies that $x=x^{\prime}$.
} 


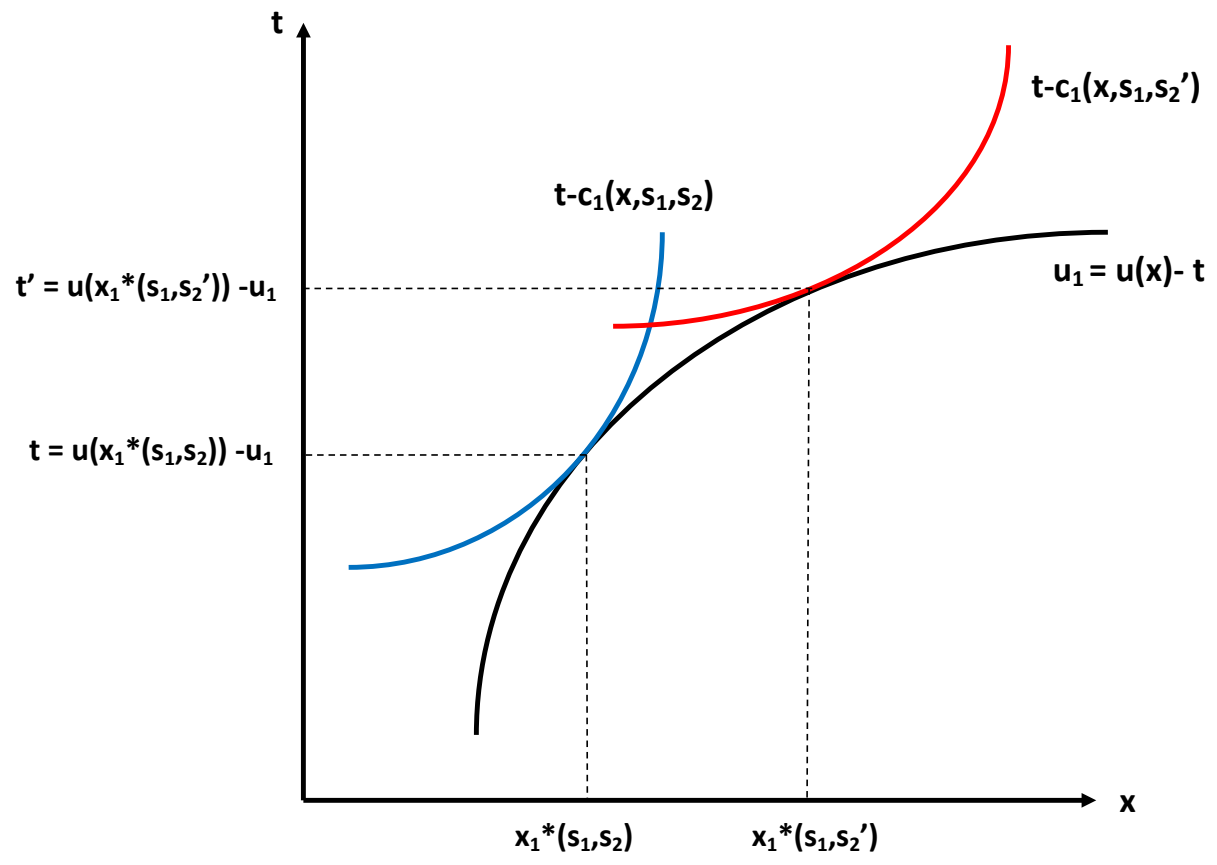

Figure 1: Preferences under interdependent values

efficient characteristics of the good that the winning seller should deliver would be different in terms of all sellers' realized signals. ${ }^{6}$

Note that the buyer's payoff does not depend on the vector of production cost signals. Consider Figure 1 again. While the buyer is indifferent between any contracts along her indifference curve, seller 1's payoff depends on both his signal and seller 2's signal. If seller 1 knew that seller 2's signal was $s_{2}$, seller 1 , with the signal $s_{1}$, would prefer the jointly ex-post efficient contract $\left(x_{1}^{*}\left(s_{1}, s_{2}\right), u\left(x_{1}^{*}\left(s_{1}, s_{2}\right)\right)-u_{1}\right)$ given the payoff level $u_{1}$ that he is willing to give to the buyer. If he knew that seller 2's signal was $s_{2}^{\prime}$, seller 1 , with the signal $s_{1}$, would prefer the jointly ex-post efficient contract $\left(x_{1}^{*}\left(s_{1}, s_{2}^{\prime}\right), u\left(x_{1}^{*}\left(s_{1}, s_{2}^{\prime}\right)\right)-u_{1}\right)$. Because the seller's preferences over those contracts along the buyer's indifference curve depend on the vector of signals, it may create incentives for a seller to offer a menu of contracts to the buyer in which multiple jointly ex-post efficient contracts are optimal for the buyer, making it possible for the buyer to choose

\footnotetext{
${ }^{6}$ In the second-price scoring auction, the winning seller is free to choose any contract as long as it matches the highest rejected score. In the second-price scoring auction, the joint ex-post efficiency is not ensured as well because there is no guarantee that the winning seller can choose the jointly ex-post efficient characteristics of the good without knowing all sellers' realized signals.
} 
the one that is most preferred by the seller given the buyer's correct perception on the vector of signals in equilibrium.

Let us consider an example with two sellers and one buyer to show the key intuition of how the first-price menu auction can achieve the jointly ex-post efficient outcome. In the first-price menu auction, the buyer advertises an open invitation for potential sellers without committing herself to a scoring rule. Sellers then simultaneously submit menus of contracts. After reviewing and evaluating all menus submitted by sellers, the buyer accepts one or none of menus. If she accepts a menu, she then chooses a contract $(x, t)$ from the menu. Those sellers whose menus are not accepted receive zero payoffs.

Example 1 Let $x-t$ be the buyer's payoff when she purchases the good with characteristic $x$ with transfer $t$. Let $t-c_{i}\left(x, s_{1}, s_{2}\right)$ be seller $i$ 's profit when he produces the good with characteristic $x$ and sells it for transfer $t$. Each seller $i$ receives either low signal $(L)$ or high signal $(H)$ for production costs. The following table shows the probabilities for each pair of signals $\left(s_{1}, s_{2}\right)$, the ex-post efficient characteristic of the good and the cost of producing the good with the ex-post efficient characteristic across sellers:

\begin{tabular}{|c|c|c|c|c|c|}
\hline $\operatorname{Pr}\left(s_{1}, s_{2}\right)$ & $\left(s_{1}, s_{2}\right)$ & $x_{1}^{*}$ & $c_{1}\left(x_{1}^{*}, s_{1}, s_{2}\right)$ & $x_{2}^{*}$ & $c_{2}\left(x_{2}^{*}, s_{1}, s_{2}\right)$ \\
\hline $3 / 8$ & $(L, L)$ & 4 & 2 & 8 & 4 \\
\hline $1 / 8$ & $(L, H)$ & 6 & 3 & 10 & 5 \\
\hline $1 / 8$ & $(H, L)$ & 16 & 11 & 12 & 8 \\
\hline $3 / 8$ & $(H, H)$ & 18 & 12 & 14 & $10 \frac{3}{4}$ \\
\hline
\end{tabular}

For simplicity, assume that the unit of monetary transfer is a quarter.

Let $m_{i}\left(s_{i}\right)$ denote the menu offered by each seller $i$ with signal $s_{i} \in\{H, L\}$ :

$$
\begin{aligned}
& m_{1}(L)=\{(4,7 / 4),(6,15 / 4)\}, m_{1}(H)=\{(16,51 / 4),(18,59 / 4)\} \\
& m_{2}(L)=\{(8,5),(12,9)\}, m_{2}(H)=\{(10,7),(14,11)\} .
\end{aligned}
$$

Note that each menu includes jointly ex-post efficient contracts and all contracts in each menu generates the same payoff level for the buyer. For example, $\left(4, \frac{7}{4}\right)$ in the menu $m_{1}(L)$ is a jointly ex-post efficient contract between seller 1 and the buyer when both sellers' signals are $L$ and $\left(6, \frac{15}{4}\right)$ is a jointly ex-post efficient contract when seller 1's signal is $L$ but seller 2's is $H$. Both contracts in $m_{1}(L)$ generates the payoff of $\frac{11}{4}$ to the buyer. The menu with jointly ex-post efficient contracts maximizes the seller's ex-post payoff conditional on a payoff level that the seller is willing to give to the buyer if the buyer in fact correctly chooses a jointly ex-post efficient contract.

For the buyer's payoff, she gets the payoff of $\frac{11}{4}$ by choosing any contract from $m_{1}(L)$, the payoff of $\frac{13}{4}$ from $m_{1}(H)$, the payoff of 3 by choosing any contract from either $m_{2}(L)$ or $m_{2}(H)$. Because $m_{i}(H) \neq m_{i}(L)$ for each seller $i$, the buyer can 
correctly infer each seller $i$ 's signal from his menu offer (i.e., this is a separating equilibrium). We examine the buyer's continuation equilibrium behavior. First of all, let us consider which menu the buyer accepts.

- If menus $m_{1}(L)$ and $m_{2}(L)$ are presented, the buyer accepts $m_{2}(L)$ because it gives her the payoff of 3 instead of $\frac{11}{4}$.

- If menus $m_{1}(L)$ and $m_{2}(H)$ are presented, the buyer accepts $m_{2}(H)$ because it gives her the payoff of 3 instead of $\frac{11}{4}$.

- If menus $\left[m_{1}(H)\right.$ and $\left.m_{2}(L)\right]$ or $\left[m_{1}(H)\right.$ and $\left.m_{2}(H)\right]$ are presented, the buyer accepts $m_{1}(H)$ because it gives her the payoff of $\frac{13}{4}$ instead of 3 .

Now consider the buyer's contract choice, upon accepting a menu, that leads to the correct choice of the jointly ex-post efficient contract.

- Note that the buyer accepts seller 2's menu, $m_{2}(L)$ or $m_{2}(H)$, only when seller 1 offers $m_{1}(L)$. The buyer knows both sellers' signals from their menu offers and therefore, upon accepting $m_{2}(L)$ or $m_{2}(H)$, she subsequently chooses the correct jointly ex-post efficient contract $(8,5)$ at $\left(s_{1}, s_{2}\right)=$ $(L, L)$ from $m_{2}(L)$ and the correct jointly ex-post efficient contract $(10,7)$ at $\left(s_{1}, s_{2}\right)=(L, H)$ from $m_{2}(H)$.

- The buyer always accepts $m_{1}(H)$ whether seller 2 offers $m_{2}(L)$ or $m_{2}(H)$. Upon accepting $m_{1}(H)$, the buyer chooses the correct jointly ex-post efficient contract $\left(16, \frac{51}{4}\right)$ at $\left(s_{1}, s_{2}\right)=(H, L)$ from $m_{1}(H)$ when seller 2 's menu is $m_{2}(L)$ but chooses the correct jointly ex-post efficient contract $\left(18, \frac{59}{4}\right)$ at $\left(s_{1}, s_{2}\right)=(H, H)$ from $m_{1}(H)$ when seller 2's menu is $m_{2}(H)$.

Because $m_{2}(L)$ is accepted only when seller 1 offers $m_{1}(L)$, the buyer always chooses $(8,5)$ upon accepting $m_{2}(L)$. For the same reason, the buyer always chooses $(10,7)$ upon accepting $m_{2}(H)$. Because $(8,5) \neq(10,7)$, seller 2 can separate his signal and induce the same contract by offering a single contract $(8,5)$ if his signal is $L$ and a single contract $(10,7)$ if his signal is $H$. However, the buyer always accepts $m_{1}(H)$ whether seller 2 's menu is $m_{2}(L)$ or $m_{2}(H)$ and therefore the jointly ex-post contracts that the buyer chooses upon accepting $m_{1}(H)$ are different, depending on whether the buyer's perception on seller 2's signal is $L$ or $H$. It implies that seller 1 with $H$ must include two different ex-post efficient contract in his menu $m_{1}(H)$ for joint ex-post efficiency. This is how the jointly ex-post efficient equilibrium is achieved through the first-price menu auction.

The equilibrium payoff for seller 1 with $L$ is zero because his menu $m_{1}(L)$ is not accepted in any case. ${ }^{7}$ The equilibrium payoff for seller 1 with $H$ is $\frac{1}{4} \times\left(\frac{51}{4}-\right.$

\footnotetext{
${ }^{7}$ Even if the buyer does not choose $m_{1}(L)$ in equilibrium, it is needed to prevent seller 2's potential deviation.
} 
11) $+\frac{3}{4} \times\left(\frac{59}{4}-12\right)=\frac{40}{16}$, where $\frac{1}{4}$ is the probability of $s_{2}=L$ conditional on $s_{1}=H$ and $\frac{3}{4}$ is the probability of $s_{2}=H$ conditional on $s_{1}=H$. The equilibrium payoff for seller 2 with $L$ is $\frac{3}{4} \times(5-4)+\frac{1}{4} \times 0=\frac{3}{4}$. The equilibrium payoff for seller 2 with $H$ is $\frac{1}{4} \times(7-5)+\frac{3}{4} \times 0=\frac{1}{2}$.

Consider a seller's deviation to an alternative menu. Because a menu may include multiple optimal contracts for the buyer, we will have the multiple continuation equilibria. Assume that the buyer correctly chooses a jointly ex-post efficient contract only if jointly ex-post efficient contracts are included in the menu and it is optimal to do so. Because a jointly ex-post efficient contract maximizes the seller's ex-post payoff conditional on the payoff that he is willing to give to the buyer, we can consider the deviation to only those menus that include jointly ex-post efficient contracts.

It is straightforward to show that there is no profitable deviation for any seller. For instance, suppose that seller 2 with $L$ is contemplating to deviate. If he wants to deviate to raise the buyer's payoff from 3 to $\frac{13}{4}$, it would be best for him to offer the menu with jointly ex-post efficient contracts, $\mathrm{m}^{\prime}=$ $\left\{\left(8, \frac{19}{4}\right),\left(12, \frac{35}{4}\right)\right\}$, expecting that the buyer would choose $\left(8, \frac{19}{4}\right)$ when seller 1 's signal is $L$ but $\left(12, \frac{35}{4}\right)$ when seller 1 's signal is $H$. Because the buyer gets the payoff of $\frac{11}{4}$ from the menu of seller 1 with signal $L$, seller 2 's menu $m^{\prime}$ will be accepted for sure if seller 1's signal is $L$. However, if seller 1 's signal is $H$, then his menu $m_{1}(H)$ also generates the payoff of $\frac{13}{4}$. In this case, the buyer chooses $m^{\prime}$ or $m_{1}(H)$ with equal probability. Hence the expected payoff from deviating to $m^{\prime}$ is $\frac{3}{4} \times\left(\frac{19}{4}-4\right)+\frac{1}{4} \times \frac{1}{2} \times\left(\frac{35}{4}-8\right)=\frac{21}{32}<\frac{3}{4}$ so that it is not profitable. Similarly, we can show that it is not profitable for seller 2 with signal $L$ to deviate in order to raise the buyer's payoff even higher or to lower it below $\frac{11}{4}$. In the same way, we can show that no seller has incentives to deviate regardless of his signals and hence a jointly ex-post efficient contract is executed in equilibrium.

The example above highlights how the jointly ex-post efficient outcome between the buyer and the winning seller can be achieved in the first-price menu auction without the buyer's commitment to a decision rule or mechanism. However, without it, a menu with multiple optimal contracts for the buyer also leaves multiple continuation equilibria. Therefore, it is natural to expect to multiple equilibria, one with each continuation equilibrium. After establishing the continuum of separating monotone equilibria in the first-price menu auction, we will examine how an equilibrium is stable in terms of the ex-post renegotiation proofness and the ex-ante robustness.

\subsection{First-Price Menu Auction}

Let us formally formulate the first-price menu auction. From now on, we will maintain the following assumptions on the buyer's and sellers' payoff functions, and on the joint density function $f$ of sellers' signals. 
Assumption 2 (i) $c_{i}(x, s)$ is bounded, measurable, and continuous in $x$ at each $s$.

(ii) $u(x)$ is bounded, measurable and continuous.

(iii) $c_{i}(x, s)$ is strictly decreasing in $s_{i}$ and non-increasing in $s_{-i}$ at each $x$.

(iv) For $x$ and $x^{\prime}$ in $\mathbb{X}$ at each $s$,

$$
\begin{aligned}
u\left(x \wedge x^{\prime}\right)-c_{i}\left(x \wedge x^{\prime}, s\right)+u\left(x \vee x^{\prime}\right)-c_{i}\left(x \vee x^{\prime}, s\right) & \geq \\
u\left(x^{\prime}\right) & -c_{i}\left(x^{\prime}, s\right)+u(x)-c_{i}(x, s) .
\end{aligned}
$$

(v) For any $x^{\prime} \geq x, c_{i}\left(x^{\prime}, s\right)-c_{i}(x, s)$ is non-decreasing in $s$.

Assumption 2.(iv) implies that the joint ex-post surplus function is supermodular in $x$ at each $s$. Assumption 2.(v) implies that $c_{i}(x, s)$ is single crossing in $s$, and it follows that the ex-post surplus function $R(x, s)$ is also single crossing in $s$.

Assumption 3 (i) $f(s)$ is measurable and strictly positive on $[0,1]^{N}$. (ii) $f\left(s \vee s^{\prime}\right) f\left(s \wedge s^{\prime}\right) \geq f(s) f\left(s^{\prime}\right)$ for all $s, s^{\prime} \in[0,1]^{N}$.

Assumption 3.(i) implies that, given any $s_{i}$, the support of $i$ 's conditional distribution on the other signals is $[0,1]$. Assumption 2.(ii) implies that signals are affiliated. The affiliation property of signals is used in establishing the existence of monotone equilibria but it is not needed to establish the results on jointly ex-post proofness and ex-ante robustness in the next section.

Formally, a menu $m_{i}$ that seller $i$ submits is a closed subset of $\mathbb{X} \times \mathbb{R} .^{8}$ Let $M_{i}$ be the set of all feasible menus available to each seller $i$. By reviewing and evaluating menu $m_{i}$, the buyer learns the maximum payoff that she can achieve from accepting $m_{i}$. For any menu $m_{i}$, define

$$
D\left(m_{i}\right) \equiv\left\{(x, t) \in m_{i}: u(x)-t \geq u\left(x^{\prime}\right)-t^{\prime}, \forall\left(x^{\prime}, t^{\prime}\right) \in m_{i}\right\} .
$$

The payoff from choosing any contract in $D\left(m_{i}\right)$ is the maximum payoff that the buyer can achieve once she accepts $m_{i}$. Given $m=\left[m_{1}, \ldots, m_{N}\right]$, let $\sigma_{i}(m) \in$ $\Delta\left(m_{i}\right)$ be the probability distribution over the contracts in the menu $m_{i}$ that the buyer choose a contract $(x, t)$ from. The buyer's strategy for contract choices $\sigma=\left[\sigma_{1}, \ldots, \sigma_{N}\right]$ is a continuation equilibrium if the support of $\sigma_{i}(m)$ is a subset

\footnotetext{
${ }^{8} \mathrm{~A}$ scoring rule or function $s: \mathbb{X} \times \mathbb{R} \rightarrow \mathbb{R}_{+}$must specify a score for every single contract in the entire space of $\mathbb{X} \times \mathbb{R}$ and it would be quite difficult for the buyer to commit ex-ante to such a rule especially when the set of characteristics $\mathbb{X}$ is highly complex and large. A menu is simply an arbitrary subset of $\mathbb{X} \times \mathbb{R}$ so that a seller can include only a few contracts $(x, t)$ from $\mathbb{X} \times \mathbb{R}$ : It is more tractable for a seller to deal with such a menu than it is for the buyer to commit ex-ante to a scoring rule that specifies scores for all contracts in the entire space of $\mathbb{X} \times \mathbb{R}$
} 
of $D\left(m_{i}\right)$ for all $m$ and all $i .^{9}$ Let $\mathcal{C}$ be the set of all continuation equilibria. Given $m=\left[m_{1}, \ldots, m_{N}\right], s=\left[s_{1}, \ldots, s_{N}\right]$, and $\sigma=\left[\sigma_{1}, \ldots, \sigma_{N}\right] \in \mathcal{C}$, seller $i$ 's payoff is

$$
v_{i}\left(m, s, \sigma_{i}\right)=\int_{(x, t) \in D\left(m_{i}\right)}\left(t-c_{i}(x, s)\right) d \sigma_{i}\left(m_{i}, m_{-i}\right)
$$

upon the buyer's acceptance of $m_{i}$.

The buyer's optimal menu acceptance behavior is as follows. She accepts the menu that gives her the highest payoff among all submitted menus if the highest payoff is non-negative. If there are two or more such menus, she accepts either of them with equal probability. Let $\mathbf{m}_{j}:[0,1] \rightarrow M_{j}$ denote seller $j$ 's menu strategy. Let $\mathbf{u}_{j}\left(s_{j}\right)$ denote the maximum payoff that the buyer can achieve by accepting $\mathbf{m}_{j}\left(s_{j}\right)$. That is, $\mathbf{u}_{j}\left(s_{j}\right)$ is the payoff that the buyer can achieve by choosing a contracting decision in $D\left(\mathbf{m}_{j}\left(s_{j}\right)\right)$. Let $u_{i}$ be the maximum payoff that the buyer can achieve by accepting seller $i$ 's menu $m_{i}$. Let $k_{i}\left(u_{i}, \mathbf{u}_{-i}\left(s_{-i}\right)\right)$ be the number of sellers such that

$$
k_{i}\left(u_{i}, \mathbf{u}_{-i}\left(s_{-i}\right)\right)=\#\left\{j: \mathbf{u}_{j}\left(s_{j}\right)=u_{i}=\max _{n} \mathbf{u}_{n}\left(s_{n}\right) \geq 0\right\}
$$

Let $\lambda_{i}\left(u_{i}, \mathbf{u}_{-i}\left(s_{-i}\right)\right)$ denote the probability that seller $i$ wins the procurement when he offers a menu $m_{i}$ that induces a maximum payoff $u_{i}$ to the buyer, given the other sellers' menu offers $\mathbf{m}_{-i}\left(s_{-i}\right)$ :

$$
\lambda_{i}\left(u_{i}, \mathbf{u}_{-i}\left(s_{-i}\right)\right)=\left\{\begin{array}{cc}
1 / k_{i}\left(u_{i}, \mathbf{u}_{-i}\left(s_{-i}\right)\right) & \text { if } k_{i}\left(u_{i}, \mathbf{u}_{-i}\left(s_{-i}\right)\right) \geq 1, \\
0 & \text { otherwise }
\end{array} .\right.
$$

When the other sellers employ menu strategies $\mathbf{m}_{-i}$, seller $i$ 's interim payoff associated with his signal $s_{i}$ and his menu offer $m_{i}$ is

$$
V_{i}\left(m_{i}, \mathbf{m}_{-i} \mid s_{i}, \sigma_{i}\right)=\mathbb{E}\left[v_{i}\left(m_{i}, \mathbf{m}_{-i}\left(S_{-i}\right), S, \sigma_{i}\right) \lambda_{i}\left(u_{i}, \mathbf{u}_{-i}\left(s_{-i}\right)\right) \mid s_{i}\right] .
$$

Definition $1\{\mathbf{m}, \sigma\}$ is a separating monotone (pure-strategy) equilibrium if

1. for all $i \in \mathcal{N}$, all $m_{i} \in M_{i}$, and a.e. $s_{i} \in[0,1], \mathbf{m}_{i}$ satisfies

$$
V_{i}\left(\mathbf{m}_{i}\left(s_{i}\right), \mathbf{m}_{-i} \mid s_{i}, \sigma_{i}\right) \geq V_{i}\left(m_{i}, \mathbf{m}_{-i} \mid s_{i}, \sigma_{i}\right),
$$

given a continuation equilibrium $\sigma \in \mathcal{C}$.

2. for all $i \in \mathcal{N}, \mathbf{m}_{i}\left(s_{i}\right) \neq \mathbf{m}_{i}\left(s_{i}^{\prime}\right)$ if $s_{i} \neq s_{i}^{\prime}$ and

${ }^{9} \mathrm{~A}$ continuation equilibrium consists of (i) the buyer's contracting decision strategies $\sigma=$ $\left[\sigma_{1}, \ldots, \sigma_{N}\right]$ and (ii) her belief on sellers' signals contingent on their menu offers, which is formed according to Bayes' rule whenever possible. A continuation equilibrium is referred as only the buyer's contracting decision strategies unless specified because it is straightforward to assign an admissible belief for a separating monotone equilibrium defined in Definition 1. 
3. for all $i \in \mathcal{N}, \mathbf{u}_{i}\left(s_{i}^{\prime}\right) \geq \mathbf{u}_{i}\left(s_{i}\right)$ if $s_{i}^{\prime} \geq s_{i}$.

Definition 1.1 is self-explanatory in that $\mathbf{m}_{i}\left(s_{i}\right)$ is the best reply for seller $i$ with signal $s_{i}$ given the other sellers' strategies and the continuation equilibrium that the buyer chooses to follow for her choice of a contract upon accepting a menu. Definition 1.2 implies that sellers with different signals separate themselves by offering different menus so that the buyer can correctly infer each seller's signal from his menu offer. A menu is sufficiently general for a seller to reveal his signal on production costs. For example, even when seller $i$ is willing to give the same level of payoff $u_{i}$ to the buyer under two different signals, he can construct two different menus $m_{i}$ and $m_{i}^{\prime}$ that can induce the same maximum payoff $u_{i}{ }^{10}$ Definition 1.3 implies the monotonicity of each seller's menu strategy in the sense that if his signal is higher, a seller offers a menu that yields a higher payoff to the buyer.

The potential difficulty in analyzing the equilibrium is the multiplicity of continuation equilibrium that will arise when a menu leaves multiple optimal contracts available to the buyer. Not only should a seller consider competing sellers' menu strategies, but he should also form a correct belief over the continuation equilibrium that the buyer would choose to follow from among the multiple continuation equilibria. Given the other sellers' non-decreasing strategies, let $A\left(u_{i}\right)$ be the event that the maximum payoff that the other sellers' menus can give to the buyer is no greater than $u_{i}$ :

$$
A\left(u_{i}\right)=\left\{s_{-i} \in[0,1]^{N-1}: \max _{j \neq i} \mathbf{u}_{j}\left(s_{j}\right) \leq u_{i}\right\}
$$

where $\mathbf{u}_{j}\left(s_{j}\right)$ is the maximum payoff that the buyer can achieve by accepting the menu $\mathbf{m}_{j}\left(s_{j}\right)$.

If $\left.\operatorname{Pr}\left(A\left(u_{i}\right)\right) \mid s_{i}\right)=0$, then $\mathbb{E}\left[\left(R(x, S)-u_{i}\right) \lambda_{i}\left(u_{i}, \mathbf{u}_{-i}\left(S_{-i}\right)\right) \mid A\left(u_{i}\right), s_{i}\right]=0$ because $\lambda_{i}\left(u_{i}, \mathbf{u}_{-i}\left(s_{-i}\right)\right)=0$ for all $s_{-i}$, given $s_{i}$ and $u_{i}$. When seller $i$ 's menu $m_{i}$ induces a maximum payoff $u_{i}$ to the buyer and she chooses the contract $(x, t)$ with $t=u(x)-u_{i}$, upon accepting $m_{i}$, seller $i$ 's interim payoff is

$$
\begin{aligned}
& \mathbb{E}\left[\left(t-c_{i}(x, S)\right)\right.\left.\lambda_{i}\left(u_{i}, \mathbf{u}_{-i}\left(S_{-i}\right)\right) \mid s_{i}\right]= \\
& \mathbb{E}\left[\left(u(x)+c_{i}(x, S)-u_{i}\right) \lambda_{i}\left(u_{i}, \mathbf{u}_{-i}\left(S_{-i}\right)\right) \mid s_{i}\right]= \\
&\left.\quad \operatorname{Pr}\left(A\left(u_{i}\right)\right) \mid s_{i}\right) \mathbb{E}\left[\left(R(x, S)-u_{i}\right) \lambda_{i}\left(u_{i}, \mathbf{u}_{-i}\left(S_{-i}\right)\right) \mid A\left(u_{i}\right), s_{i}\right] .
\end{aligned}
$$

Consider the jointly interim efficient and the jointly ex-post efficient characteristics of the good when seller $i$ sells the good to the buyer given the other

\footnotetext{
${ }^{10}$ Although $m_{i}$ and $m_{i}^{\prime}$ induce the same maximum payoff $u_{i}$ for the buyer, the sets of optimal contracts for the buyer can be different $\left(D\left(m_{i}\right) \neq D\left(m_{i}^{\prime}\right)\right)$ so that $m_{i} \neq m_{i}^{\prime}$. Alternatively, $m_{i}$ and $m_{i}^{\prime}$ may have the same set of optimal contracts for the buyer $\left(D\left(m_{i}\right)=D\left(m_{i}^{\prime}\right)\right)$ but they can have different contracts that yield payoffs lower than $u_{i}$ so that $m_{i} \neq m_{i}^{\prime}$.
} 
sellers' non-decreasing strategies. When $u_{i}$ is the maximum payoff that the buyer can achieve from a menu $m_{i}$ offered by seller $i$ with signal $s_{i}$, and she chooses $(x, t)$ with $t=u(x)-u_{i}$ from $m_{i}$, the joint interim surplus conditional on $\left(A\left(u_{i}\right), s_{i}\right)$ becomes $\mathbb{E}\left[R_{i}(x, S) \lambda_{i}\left(u_{i}, \mathbf{u}_{-i}\left(S_{-i}\right)\right) \mid A\left(u_{i}\right), s_{i}\right]$. Given $\left(A\left(u_{i}\right), s_{i}, \mathbf{u}_{-i}\right)$, let

$$
X_{i}^{e}\left(A\left(u_{i}\right), s_{i}, \mathbf{u}_{-i}\right)=\underset{x \in \mathbb{X}}{\arg \max } \mathbb{E}\left[R_{i}(x, S) \lambda_{i}\left(u_{i}, \mathbf{u}_{-i}\left(S_{-i}\right)\right) \mid A\left(u_{i}\right), s_{i}\right]
$$

be the set of jointly interim efficient characteristics of the good.

Because $R_{i}(x, s)$ is continuous in $x$ at each $s$ and $\lambda_{i}\left(u_{i}, \mathbf{u}_{-i}\left(s_{-i}\right)\right)$ is a real number in [0,1], $R_{i}(x, s) \lambda_{i}\left(u_{i}, \mathbf{u}_{-i}\left(s_{-i}\right)\right)$ is continuous in $x$ at each $s$. It implies that $\mathbb{E}\left[R_{i}(x, S) \lambda_{i}\left(u_{i}, \mathbf{u}_{-i}\left(S_{-i}\right)\right) \mid A\left(u_{i}\right), s_{i}\right]$ is continuous in $x$. Because $\mathbb{X}$ is compact and $\mathbb{E}\left[R_{i}(x, S) \lambda_{i}\left(u_{i}, \mathbf{u}_{-i}\left(S_{-i}\right)\right) \mid A\left(u_{i}\right), s_{i}\right]$ is continuous in $x, X_{i}^{e}\left(A\left(u_{i}\right), s_{i}, \mathbf{u}_{-i}\right)$ is non-empty by Weierstrass' Theorem. Let $x_{i}^{e}\left(u_{i}, s_{i}, \mathbf{u}_{-i}\right)$ denote a typical element in $X_{i}^{e}\left(A\left(u_{i}\right), s_{i}, \mathbf{u}_{-i}\right)$. If $\mathbb{E}\left[\left(R(x, S)-u_{i}\right) \lambda_{i}\left(u_{i}, \mathbf{u}_{-i}\left(S_{-i}\right)\right) \mid A\left(u_{i}\right), s_{i}\right]=0$ for all $x \in$ $\mathbb{X}$, then let $X_{i}^{e}\left(u_{i}, s_{i}, \mathbf{u}_{-i}\right)=\left\{x_{\circ}\right\}$, where $x_{\circ} \in \mathbb{X}$ denotes the status-quo action such as no trading, that makes $R_{i}\left(x_{\circ}, s\right)=v_{i}\left(x_{\circ}, s\right)+u\left(x_{\circ}\right)=0$ for all $s \in[0,1]$. Let $x \geq x_{\circ}$ for all $x \in \mathbb{X}$.

Suppose that the buyer will always choose the same contract from a seller's menu regardless of her perception on all sellers' production cost signals after she evaluates all menus. In equilibrium, the same contract that the buyer chooses must be a jointly interim efficient contract because it is always feasible for a seller to submit a degenerate menu consisting of a single contract. Therefore, the equilibrium is only jointly interim efficient even though sellers' signals are fully revealed to the buyer in equilibrium.

Contrarily, suppose that the buyer will always choose a jointly ex-post efficient contract from a seller's menu when it is available in the menu and optimal to the buyer. Consider the jointly ex-post efficient contract $\left(x_{i}^{*}(s), u\left(x_{i}^{*}(s)\right)-\mathbf{u}_{i}\left(s_{i}\right)\right)$ associated with the maximum payoff $\mathbf{u}_{i}\left(s_{i}\right)$ that seller $i$ is willing to give to the buyer at each $s_{i}$, where $s=\left(s_{i}, s_{-i}\right)$. Given $s_{i}$ and $\mathbf{u}_{i}\left(s_{i}\right)$, seller $i$ may include every jointly ex-post efficient contract $\left(x_{i}^{*}(s), u\left(x_{i}^{*}(s)\right)-\mathbf{u}_{i}\left(s_{i}\right)\right)$ for every $s_{-i}$. Because the buyer is fully aware of sellers' production cost signals after evaluating their menus in a truthful monotone equilibrium, she can choose the jointly expost efficient contract $\left(x_{i}^{*}(s), u\left(x_{i}^{*}(s)\right)-\mathbf{u}_{i}\left(s_{i}\right)\right)$ from seller $i$ 's menu at every $s$ as long as $\mathbf{u}_{i}\left(s_{i}\right)$ is the maximum payoff that she can achieve from accepting seller $i$ 's menu. When all sellers believe that the buyer would always choose such a jointly ex-post efficient contract, they will submit their menus accordingly and the equilibrium is jointly ex-post efficient. ${ }^{11}$

\footnotetext{
${ }^{11}$ As in first-price auctions with asymmetric bidders, the equilibrium may not be fully expost efficient with asymmetric sellers even when the buyer always chooses a jointly ex-post efficient contract from the winning seller's menu. This is because the buyer may not accept a menu offered by a seller with whom she can maximize the joint ex-post surplus. If sellers are ex-ante homogenous and the (joint) probability distribution on signals is symmetric as assumed in many applications, then the jointly ex-post efficient equilibrium is fully ex-post efficient.
} 
When a menu includes multiple optimal contracts for the buyer, it leads to multiple continuation equilibria. If it was optimal, the buyer could always choose a jointly ex-post efficient contract from a menu. Alternatively, the buyer may choose the same optimal contract regardless of her perception on sellers' signals. In this case, the contract that the buyer chooses must be jointly interim efficient because a seller can always offer a degenerate menu consisting of a single contract. Finally, the buyer may even randomize her choice between a jointly ex-post efficient contract and a jointly interim efficient one in a menu.

\section{Separating Monotone Equilibria}

Because the buyer cannot commit herself to a scoring rule, sellers' menu offers depend on their beliefs over how likely the buyer will choose a jointly ex-post efficient contract in a continuation equilibrium when it is one of the optimal contracts for her within a menu. We establish the existence of a separating monotone equilibrium by taking two steps.

As the first step, this section considers a modified auction in which (i) each seller $i$ directly submits the buyer's payoff bid $u_{i}$ along with the characteristics $x_{i}$ of the good and (ii) the buyer knows sellers' signals but each seller knows only his own signal. When the buyer accepts contract $\left(u_{i}, x_{i}\right)$ from seller $i$ in this modified auction, she chooses $x_{i}$ and makes the monetary payment $t_{i}=u\left(x_{i}\right)-u_{i}$ with probability $1-\tau_{i}$ so that $\left(x_{i}, u\left(x_{i}\right)-u_{i}\right)$ generates her a payoff that exactly matches the payoff bid $u_{i}$ that seller $i$ submits. With probability $\tau_{i}$, the buyer chooses the jointly ex-post efficient contract $\left(x_{i}^{*}(s), u\left(x_{i}^{*}(s)\right)-u_{i}\right)$, at each $s$, that generates the payoff bid $u_{i}$ submitted by seller $i$. We complete the first step by showing the existence of a monotone equilibrium in this modified auction with any arbitrary $\tau=\left[\tau_{1}, \ldots, \tau_{N}\right] \in[0,1]^{N}$.

In the second step, we show that for a monotone equilibrium in this modified auction with any given $\tau$, there exists a payoff-equivalent separating monotone equilibrium in the first-price menu auction in which the buyer chooses, upon accepting a menu, a jointly ex-post efficient contract with probability $\tau_{i}$ and a jointly interim efficient contract with probability $1-\tau_{i}$ from each seller $i$ 's equilibrium menu. Because there exists a separating monotone equilibrium for any given $\tau \in[0,1]^{N}$, there exists a continuum of separating monotone equilibria that spans the entire space of $[0,1]^{N}$.

Note that the modified auction is not the one that the buyer actually uses. We construct the modified auction and establish monotone equilibrium in this modified auction only because it is used in establishing separating monotone equilibrium in the first-price menu auction.

First consider the modified auction. In the modified auction, each seller $i$ submits a bid $\left(u_{i}, x_{i}\right)$ from $U_{i} \times \mathbb{X}$, where $U_{i}=[0, \infty) \cup\left\{u_{\circ}\right\}$ with $u_{\circ}<0$. Let $u_{i}$ 
be a payoff bid and $x_{i}$ be a bid for the characteristics of the good. When seller $i$ submits $u_{\circ}$, he must submit $x_{\circ}$ along with it. Let $\left(u_{\circ}, x_{\circ}\right)$ be the losing bid regardless of the bids submitted by other sellers. If $\left(u_{i}, x_{i}\right) \neq\left(u_{\circ}, x_{\circ}\right)$, it is called a serious bid. Assume that each seller knows only his own signal but the buyer knows every seller's signal. The buyer chooses a seller whose payoff bid is the highest non-negative bid from among all sellers' payoff bids. If there are two or more sellers who submit the highest non-negative payoff bid, the buyer chooses either of them with equal probability. When seller $i$ wins the procurement with $\left(u_{i}, x_{i}\right) \in U_{i} \times \mathbb{X}$, the buyer buys the good with characteristics $x_{i}$ from seller $i$ by paying $t_{i}=u\left(x_{i}\right)-u_{i}$ with probability $1-\tau_{i}$, but she buys the good with jointly ex-post efficient characteristics $x_{i}^{*}(s) \in X_{i}^{*}(s)$ by paying $t_{i}=u\left(x_{i}^{*}(s)\right)-u_{i}$ for all $s \in[0,1]^{N}$ with probability $\tau_{i}$. We fix $\tau=\left[\tau_{1}, \ldots, \tau_{N}\right]$ as part of the procurement rule and it is known to sellers.

We now examine the existence of a monotone equilibrium in the modified auction with any given $\tau=\left[\tau_{1}, \ldots, \tau_{N}\right] \in[0,1]^{N}$. Seller $i$ 's strategy is a pair consisting of a payoff bidding function, $\mathbf{u}_{i}:[0,1] \rightarrow U_{i}$, and a bidding function for the characteristics of the good, $\mathbf{x}_{i}:[0,1] \rightarrow \mathbb{X}$. Suppose that the other sellers' strategies are non-decreasing: i.e., for all $j \neq i, \mathbf{u}_{j}\left(s_{j}^{\prime}\right) \geq \mathbf{u}_{j}\left(s_{j}\right)$ and $\mathbf{x}_{j}\left(s_{j}^{\prime}\right) \geq \mathbf{x}_{j}\left(s_{j}\right)$ if $s_{j}^{\prime} \geq s_{j}$. Seller $i$ 's interim payoff associated with submitting $\left(u_{i}, x_{i}\right)$ is

$$
\begin{aligned}
& V_{i}\left(u_{i}, x_{i}, \mathbf{u}_{-i} \mid s_{i}\right)= \\
& \left(1-\tau_{i}\right) \operatorname{Pr}\left(A\left(u_{i}\right) \mid s_{i}\right) \mathbb{E}\left[\left(R_{i}\left(x_{i}, S\right)-u_{i}\right) \lambda_{i}\left(u_{i}, \mathbf{u}_{-i}\left(S_{-i}\right)\right) \mid A\left(u_{i}\right), s_{i}\right]+ \\
& \tau_{i} \operatorname{Pr}\left(A\left(u_{i}\right) \mid s_{i}\right) \mathbb{E}\left[\left(R_{i}\left(x_{i}^{*}(S), S\right)-u_{i}\right) \lambda_{i}\left(u_{i}, \mathbf{u}_{-i}\left(S_{-i}\right)\right) \mid A\left(u_{i}\right), s_{i}\right] .
\end{aligned}
$$

Alternatively, we can express seller $i$ 's interim payoff as follows. First, define the surplus between seller $i$ and the buyer as

$$
R_{i}^{\tau}\left(x_{i}, s\right)=\left(1-\tau_{i}\right)\left[v_{i}\left(x_{i}, s\right)+u\left(x_{i}\right)\right]+\tau_{i}\left[v_{i}\left(x_{i}^{*}(s), s\right)+u\left(x_{i}^{*}(s)\right)\right]
$$

when seller $i$ wins the procurement with a characteristics bid $x_{i}$ and an arbitrary payoff bid. Because of Assumption 1.(v)-(vi), $R_{i}^{\tau}\left(x_{i}, s\right)$ is supermodular in $x_{i}$ and $R_{i}^{\tau}\left(x_{i}^{\prime}, s\right)-R_{i}^{\tau}\left(x_{i}, s\right)$ is non-decreasing in $s$ whenever $x_{i}^{\prime} \geq x_{i}$. Seller $i$ 's interim payoff associated with submitting $\left(u_{i}, x_{i}\right)$ can be expressed as

$$
\begin{aligned}
V_{i}\left(u_{i}, x_{i}, \mathbf{u}_{-i} \mid s_{i}\right) & = \\
& \operatorname{Pr}\left(A\left(u_{i}\right) \mid s_{i}\right) \mathbb{E}\left[\left(R_{i}^{\tau}\left(x_{i}, S\right)-u_{i}\right) \lambda_{i}\left(u_{i}, \mathbf{u}_{-i}\left(S_{-i}\right)\right) \mid A\left(u_{i}\right), s_{i}\right] .
\end{aligned}
$$

Theorem 1 below establishes the existence of a monotone equilibrium in the modified auction with any given $\tau=\left[\tau_{1}, \ldots, \tau_{N}\right] \in[0,1]^{N}$.

Theorem 1 For any given $\tau=\left[\tau_{1}, \ldots, \tau_{N}\right] \in[0,1]^{N}$, the modified auction possesses a monotone equilibrium $\left\{\left(\hat{\mathbf{u}}_{1}, \hat{\mathbf{x}}_{1}\right), \ldots,\left(\hat{\mathbf{u}}_{N}, \hat{\mathbf{x}}_{N}\right)\right\}$. 
Theorem 1 is closely related to Reny $(2011)$ because a bid $\left(u_{i}, x_{i}\right)$ is multidimensional. Theorem 4.1 in Reny (2011) demonstrates that if certain conditions (G.1-G.5 in Reny 2011) on players' actions, payoff functions, and types are satisfied and each player's set of monotone best replies is nonempty and join-closed whenever the others employ monotone pure strategies, then a Bayesian game possesses a monotone equilibrium. In our modified auction, let $B_{i}\left(s_{i}\right)$ be the set of best replies for seller $i$ with signal $s_{i}$ when the other sellers employ monotone strategies so that $B_{i}\left(s_{i}\right)$ includes every $\left(u_{i}, x_{i}\right)$ that maximizes seller $i$ 's interim payoff given the other sellers' monotone strategies.

$B_{i}(\cdot)$ is monotone if for any monotone strategies of the other sellers $\left(\mathbf{u}_{-i}, \mathbf{x}_{-i}\right)$, whenever $\left(u_{i}, x_{i}\right) \in B_{i}\left(s_{i}\right)$ and $\left(u_{i}^{\prime}, x_{i}^{\prime}\right) \in B_{i}\left(s_{i}^{\prime}\right)$ for $s_{i}^{\prime} \geq s_{i}$, then $\left(u_{i} \vee u_{i}^{\prime}, x_{i} \vee x_{i}^{\prime}\right) \in$ $B_{i}\left(s_{i}^{\prime}\right)$. This monotonicity is strictly weaker than the increasing property of best replies in the strong order set (Milgrom and Shannon 1994). $B_{i}(\cdot)$ is join-closed if $\left(u_{i}, x_{i}\right) \in B_{i}\left(s_{i}\right)$, and $\left(u_{i}^{\prime}, x_{i}^{\prime}\right) \in B_{i}\left(s_{i}\right)$ implies that $\left(u_{i} \vee u_{i}^{\prime}, x_{i} \vee x_{i}^{\prime}\right) \in B_{i}\left(s_{i}\right)$.

Reny establishes the existence of a monotone equilibrium ingeniously by utilizing a fixed-point theorem based on contractibility rather than the convexity of best replies (Athey 2001, McAdams 2006). Proposition 4.4 in Reny (2011) provides a convenient sufficient condition for the existence of a monotone equilibrium: If the set of bids for each player is a lattice and each player's interim payoff function is weakly single crossing and weakly quasisupermodular, then each player' set of monotone best replies is non-empty and join-closed. To see this point, fix the other sellers' monotone strategies. Each seller $i$ 's interim payoff function is weakly single crossing if, for all pairs of bids $\left(u_{i}^{\prime}, x_{i}^{\prime}\right) \geq\left(u_{i}, x_{i}\right)$ and all pairs of signals $s_{i}^{\prime} \geq s_{i}$,

$$
V_{i}\left(u_{i}^{\prime}, x_{i}^{\prime}, \mathbf{u}_{-i} \mid s_{i}\right) \geq V_{i}\left(u_{i}, x_{i}, \mathbf{u}_{-i} \mid s_{i}\right) \Longrightarrow V_{i}\left(u_{i}^{\prime}, x_{i}^{\prime}, \mathbf{u}_{-i} \mid s_{i}^{\prime}\right) \geq V_{i}\left(u_{i}, x_{i}, \mathbf{u}_{-i} \mid s_{i}^{\prime}\right) .
$$

Each seller $i$ 's interim payoff function is weakly quasisupermodular if, for all $\left(u_{i}, x_{i}\right),\left(u_{i}^{\prime}, x_{i}^{\prime}\right) \in U_{i} \times \mathbb{X}$ and all $s_{i} \in[0,1]$

$$
\begin{aligned}
V_{i}\left(u_{i}, x_{i}, \mathbf{u}_{-i} \mid s_{i}\right) \geq V_{i}\left(u_{i} \wedge u_{i}^{\prime}, x_{i} \wedge\right. & \left.x_{i}^{\prime}, \mathbf{u}_{-i} \mid s_{i}\right) \Longrightarrow \\
& V_{i}\left(u_{i} \vee u_{i}^{\prime}, x_{i} \vee x_{i}^{\prime}, \mathbf{u}_{-i} \mid s_{i}\right) \geq V_{i}\left(u_{i}^{\prime}, x_{i}^{\prime}, \mathbf{u}_{-i} \mid s_{i}\right) .
\end{aligned}
$$

The idea behind these conditions is straightforward. Consider any pair of best replies such that $\left(u_{i}, x_{i}\right) \in B_{i}\left(s_{i}\right)$ and $\left(u_{i}^{\prime}, x_{i}^{\prime}\right) \in B_{i}\left(s_{i}^{\prime}\right)$ for $s_{i}^{\prime} \geq s_{i}$. Because $\left(u_{i}, x_{i}\right) \in B_{i}\left(s_{i}\right)$, we have

$$
V_{i}\left(u_{i}, x_{i}, \mathbf{u}_{-i} \mid s_{i}\right) \geq V_{i}\left(u_{i} \wedge u_{i}^{\prime}, x_{i} \wedge x_{i}^{\prime}, \mathbf{u}_{-i} \mid s_{i}\right) .
$$

By weakly single crossing, the inequality above implies

$$
V_{i}\left(u_{i}, x_{i}, \mathbf{u}_{-i} \mid s_{i}^{\prime}\right) \geq V_{i}\left(u_{i} \wedge u_{i}^{\prime}, x_{i} \wedge x_{i}^{\prime}, \mathbf{u}_{-i} \mid s_{i}^{\prime}\right) .
$$


Applying weakly quasisupermodularity, this inequality implies

$$
V_{i}\left(u_{i} \vee u_{i}^{\prime}, x_{i} \vee x_{i}^{\prime}, \mathbf{u}_{-i} \mid s_{i}^{\prime}\right) \geq V_{i}\left(u_{i}^{\prime}, x_{i}^{\prime}, \mathbf{u}_{-i} \mid s_{i}^{\prime}\right) .
$$

Because $\left(u_{i}^{\prime}, x_{i}^{\prime}\right) \in B_{i}\left(s_{i}^{\prime}\right)$, the last inequality implies $\left(u_{i} \vee u_{i}^{\prime}, x_{i} \vee x_{i}^{\prime}\right) \in B_{i}\left(s_{i}^{\prime}\right)$ so that $B_{i}(\cdot)$ is monotone. By setting up $s_{i}=s_{i}^{\prime}$, the join-closedness follows as well.

However, a seller's interim payoff function in the modified auction may fail to be weakly single crossing and/or weakly quasisupermodular at irrational bids or rational bids with a positive probability of ties, as a seller's interim payoff function in first price auctions with single dimensional bids (i.e., real numbers) may fail to satisfy Athey's (2001) single crossing property. ${ }^{12}$ Reny and Zamir (2004) avoid this problem and establish the existence of a monotone equilibrium in a first price auction with single dimensional bids by considering limits of ever finer finite bid sets such that no two sellers have a common serious bid and by recalling that single crossing is needed only at individually rational bids, i.e., "individually rational tieless single-crossing condition" (IRT-SCC).

For the existence of a monotone equilibrium in the modified auction, this paper proposes the "tieless supermodular condition" (TLS-SMC) and extends Reny and Zamir's IRT-SCC. TLS-SMC, together with IRT-SCC, ensures both the weakly single crossing condition and the weakly quasisupermodular condition at individually rational tieless bids. We formally define TLS-SMC in Definition 2 below.

Definition 2 The modified auction satisfies TLS-SMC if, for each seller $i$, any $\left(u_{i}, x_{i}\right),\left(u_{i}^{\prime}, x_{i}^{\prime}\right)$ with $\operatorname{Pr}\left[u_{\circ}<\max _{j \neq i} \mathbf{u}_{j}\left(s_{j}\right)=u_{i}\right.$ or $\left.u_{i}^{\prime}\right]=0$ given any nondecreasing payoff bidding functions $\mathbf{u}_{-i}$ of the other sellers, the following inequality holds:

$$
\begin{aligned}
V_{i}\left(u_{i} \vee u_{i}^{\prime}, x_{i} \vee x_{i}^{\prime}, \mathbf{u}_{-i} \mid s_{i}\right)- & V_{i}\left(u_{i}^{\prime}, x_{i}^{\prime}, \mathbf{u}_{-i} \mid s_{i}\right) \geq \\
& V_{i}\left(u_{i}, x_{i}, \mathbf{u}_{-i} \mid s_{i}\right)-V_{i}\left(u_{i} \wedge u_{i}^{\prime}, x_{i} \wedge x_{i}^{\prime}, \mathbf{u}_{-i} \mid s_{i}\right) .
\end{aligned}
$$

TLS-SMC implies that for any two tieless serious bids $\left(u_{i}, x_{i}\right)$ and $\left(u_{i}^{\prime}, x_{i}^{\prime}\right)$,

$$
\begin{aligned}
V_{i}\left(u_{i}, x_{i}, \mathbf{u}_{-i} \mid s_{i}\right) \geq V_{i}\left(u_{i} \wedge u_{i}^{\prime}, x_{i} \wedge x_{i}^{\prime}, \mathbf{u}_{-i} \mid s_{i}\right) \Longrightarrow \\
V_{i}\left(u_{i} \vee u_{i}^{\prime}, x_{i} \vee x_{i}^{\prime}, \mathbf{u}_{-i} \mid s_{i}\right) \geq V_{i}\left(u_{i}^{\prime}, x_{i}^{\prime}, \mathbf{u}_{-i} \mid s_{i}\right)
\end{aligned}
$$

and

$$
\begin{aligned}
V_{i}\left(u_{i}^{\prime}, x_{i}^{\prime}, \mathbf{u}_{-i} \mid s_{i}\right) \geq V_{i}\left(u_{i} \vee u_{i}^{\prime}, x_{i} \vee\right. & \left.x_{i}^{\prime}, \mathbf{u}_{-i} \mid s_{i}\right) \Longrightarrow \\
& V_{i}\left(u_{i} \wedge u_{i}^{\prime}, x_{i} \wedge x_{i}^{\prime}, \mathbf{u}_{-i} \mid s_{i}\right) \geq V_{i}\left(u_{i}, x_{i}, \mathbf{u}_{-i} \mid s_{i}\right) .
\end{aligned}
$$

The extension of Reny and Zamir's IRT-SCC is given below.

\footnotetext{
${ }^{12}$ See the examples in Reny and Zamir (2004) that show the failure of the single crossing property.
} 
Definition 3 The modified auction satisfies IRT-SCC if, for each seller $i$, all pairs of $\left(\bar{u}_{i}, \bar{x}_{i}\right)$ and $\left(\underline{u}_{i}, \underline{x}_{i}\right)$ such that (i) $\bar{u}_{i} \geq \underline{u}_{i}$ and $\bar{x}_{i} \geq \underline{x}_{i}$ and (ii) $\operatorname{Pr}\left[u_{\circ}<\right.$ $\max _{j \neq i} \mathbf{u}_{j}\left(s_{j}\right)=\underline{u}_{i}$ or $\left.\bar{u}_{i}\right]=0$ given any non-decreasing payoff bidding functions $\mathbf{u}_{-i}$ for the other sellers, the following condition is satisfied: If $V_{i}\left(\bar{u}_{i}, \bar{x}_{i}, \mathbf{u}_{-i} \mid s_{i}\right) \geq$ 0 , then

$$
V_{i}\left(\bar{u}_{i}, \bar{x}_{i}, \mathbf{u}_{-i} \mid s_{i}\right) \geq V_{i}\left(\underline{u}_{i}, \underline{x}_{i}, \mathbf{u}_{-i} \mid s_{i}\right) \Longrightarrow V_{i}\left(\bar{u}_{i}, \bar{x}_{i}, \mathbf{u}_{-i} \mid s_{i}^{\prime}\right) \geq V_{i}\left(\underline{u}_{i}, \underline{x}_{i}, \mathbf{u}_{-i} \mid s_{i}^{\prime}\right)
$$

for all $s_{i}^{\prime} \geq s_{i}$. If $V_{i}\left(\underline{u}_{i}, \underline{x}_{i}, \mathbf{u}_{-i} \mid s_{i}^{\prime}\right) \geq 0$ for any $s_{i}^{\prime} \geq s_{i}$, then

$$
V_{i}\left(\underline{u}_{i}, \underline{x}_{i}, \mathbf{u}_{-i} \mid s_{i}^{\prime}\right) \geq V_{i}\left(\bar{u}_{i}, \bar{x}_{i}, \mathbf{u}_{-i} \mid s_{i}^{\prime}\right) \Longrightarrow V_{i}\left(\underline{u}_{i}, \underline{x}_{i}, \mathbf{u}_{-i} \mid s_{i}\right) \geq V_{i}\left(\bar{u}_{i}, \bar{x}_{i}, \mathbf{u}_{-i} \mid s_{i}\right) .
$$

TLS-SMC requires that bids be serious and tieless but the individual rationality of bids (i.e., $\left.V_{i}\left(\bar{u}_{i}, \bar{x}_{i}, \mathbf{u}_{-i} \mid s_{i}\right) \geq 0, V_{i}\left(\underline{u}_{i}, \underline{x}_{i}, \mathbf{u}_{-i} \mid s_{i}^{\prime}\right) \geq 0\right)$ is also required for IRT-SCC. Lemma 1 enables us to apply Theorem 4.1 in Reny (2011) when proving the existence of a monotone equilibrium.

Lemma 1 The modified auction satisfies TLS-SMC and IRT-SCC.

We first consider the finite modified auction in which (i) the set of feasible bids for each seller $i$ is given by $U_{i}^{n} \times \mathbb{X}$, where $U_{i}^{n}$ is a finite set including $u_{\circ}$ and satisfies that for any $u_{i} \in U_{i}^{n}, u_{i} \neq 0$ implies that $u_{i} \geq 0$, and (ii) $U_{i}^{n}$ and $U_{j}^{n}$ do not have any common serious payoff bids for any $i \neq j$. Therefore, TLS-SMC and IRT-SCC are satisfied in the finite modified auction. As in Reny and Zamir (2004) and Athey (2001), each seller is restricted to submit the losing bid $\left(u_{\circ}, x_{\circ}\right)$ whenever his signal is in $[0, \varepsilon)$, where $\varepsilon=1 / n$ with $n$ being a natural number. In the finite modified auction, $n$ is fixed so that $[0, \varepsilon)$ has positive measure but the measure of $[0, \varepsilon)$ converges to zero as $n \rightarrow \infty$.

Lemma 2 The finite modified auction possesses a monotone equilibrium.

Let $\left\{\left(\mathbf{u}_{1}^{n}, \mathbf{x}_{1}^{n}\right), \ldots,\left(\mathbf{u}_{N}^{n}, \mathbf{x}_{N}^{n}\right)\right\}$ be a monotone equilibrium in the modified auction game $G^{n}$, with an arbitrary $\tau=\left[\tau_{1}, \ldots, \tau_{N}\right] \in[0,1]^{N}$, in which seller $i$ 's finite set of payoff bids is denoted by $U_{i}^{n}$ and, hence, the set of payoff and characteristics bids is $U_{i}^{n} \times \mathbb{X}$. We assume that $U_{i}^{n-1} \subseteq U_{i}^{n}$ and that $\bigcup_{n} U_{i}^{n}$ is dense in $U_{i}$. The proof of Theorem 1 is completed by showing that the limit $\left\{\left(\hat{\mathbf{u}}_{1}, \hat{\mathbf{x}}_{1}\right), \ldots,\left(\hat{\mathbf{u}}_{N}, \hat{\mathbf{x}}_{N}\right)\right\}$ of $\left\{\left(\mathbf{u}_{1}^{n}, \mathbf{x}_{1}^{n}\right), \ldots,\left(\mathbf{u}_{N}^{n}, \mathbf{x}_{N}^{n}\right)\right\}$ is a monotone equilibrium in the modified auction without restrictions on the sets of payoff bids. As in Reny and Zamir (2004), we carefully show the following two points. First of all, we show that, given the limit bidding functions $\hat{\mathbf{u}}_{-i}$ of the other sellers, seller $i$ 's interim payoff associated with any bid $\left(u_{i}, x_{i}\right)$ can be approximated arbitrarily well or he can improve upon his payoff by slightly increasing his payoff bid, given the same action bid $x_{i}$, that does not tie the other sellers' payoff bids with probability 
one. Secondly, we are concerned that the possibility of ties may lead the limiting payoffs to differ from the payoffs at the limit strategies. It is shown that the probability that, under $\hat{\mathbf{u}}$, two or more sellers simultaneously submit the highest payoff bid above $u_{\circ}$ is zero so that the limiting payoff for seller $i$ with $s_{i}$ is always obtained by employing the limit bids $\left(\hat{\mathbf{u}}_{i}\left(s_{i}\right), \hat{\mathbf{x}}_{i}\left(s_{i}\right)\right)$ given the other sellers' limit bidding functions, $\hat{\mathbf{u}}_{-i}$.

Finally, we establish a continuum of separating monotone equilibria in the first-price menu auction.

Theorem 2 For a monotone equilibrium $\left\{\left(\hat{\mathbf{u}}_{1}, \hat{\mathbf{x}}_{1}\right), \ldots,\left(\hat{\mathbf{u}}_{N}, \hat{\mathbf{x}}_{N}\right)\right\}$ in the modified auction with any given $\tau=\left[\tau_{1}, \ldots, \tau_{N}\right] \in[0,1]^{N}$, there exists a separating monotone equilibrium $\left\{\mathbf{m}_{1}^{\tau}, \ldots, \mathbf{m}_{N}^{\tau}, \sigma^{\tau}\right\}$ in the first-price menu auction such that

$$
V_{i}\left(\mathbf{m}_{i}^{\tau}\left(s_{i}\right), \mathbf{m}_{-i}^{\tau} \mid s_{i}, \sigma_{i}^{\tau}\right)=V_{i}\left(\hat{\mathbf{u}}_{i}\left(s_{i}\right), \hat{\mathbf{x}}_{i}\left(s_{i}\right), \hat{\mathbf{u}}_{-i} \mid s_{i}\right)
$$

for each $i$ and all $s_{i}$.

Theorem 2 demonstrates that for any monotone equilibrium in the modified auction with any given $\tau=\left[\tau_{1}, \ldots, \tau_{N}\right] \in[0,1]^{N}$, we can find a payoff-equivalent separating monotone equilibrium in the first-price menu auction in which each seller $i$ believes that the buyer, upon accepting his equilibrium menu, would optimally choose a jointly ex-post efficient contract with probability $\tau_{i}$ and a jointly interim efficient contract with probability $1-\tau_{i}$. Because there exists a separating monotone equilibrium for any given $\tau \in[0,1]^{N}$, there exists the continuum of separating monotone equilibria that spans $[0,1]^{N}$, the entire space of sellers' beliefs on how likely the buyer would choose either a jointly ex-post efficient contract or a jointly interim efficient contract.

\section{Menus and Interdependent Values}

Given the continuum of separating monotone equilibria, equilibrium allocation is bounded below by jointly interim efficiency and above by joint ex-post efficiency. In following subsections, we study the stability of the equilibria in two fronts. First of all, we study which equilibrium gives no incentives for jointly ex-post renegotiation to the buyer and the winning seller. Secondly, even before the buyer chooses a winning seller, a seller may consider deviating from his menu (i.e., change his menu). Prior to the buyer's choice of a winning seller, sellers' incentives to deviate depend on the continuation equilibrium that they believe the buyer would follow following their deviations. Some equilibrium may be supported only through a particular continuation equilibrium because a seller may want to deviate under any other continuation equilibrium. In this sense, we study how sensitive an equilibrium is to sellers' beliefs on the continuation 
equilibrium or how ex-ante robust it is to sellers' beliefs on the continuation equilibrium.

We have demonstrated that the degree of efficiency in the first-price menu auction with menus is dependent on sellers' beliefs on how the buyer will use her information on production costs when choosing a contract from the menu. Because the buyer cannot commit herself to scoring rules, there exists a continuum of separating monotone equilibria. It is important to find out whether there is an equilibrium that is more stable than others.

Fix a separating monotone equilibrium $\left\{\mathbf{m}_{1}^{\tau}, \ldots, \mathbf{m}_{N}^{\tau}, \sigma^{\tau}\right\}$ given a vector $\tau=$ $\left[\tau_{1}, \ldots, \tau_{N}\right]$. Let $\left\{\left(\hat{\mathbf{u}}_{1}, \hat{\mathbf{x}}_{1}\right), \ldots,\left(\hat{\mathbf{u}}_{N}, \hat{\mathbf{x}}_{N}\right)\right\}$ be its corresponding payoff-equivalent monotone equilibrium in the modified auction. Let seller $i$ be the winning seller when the signal vector is $s=\left[s_{1}, \ldots, s_{N}\right]$. Seller $i$ 's expected ex-post payoff is then

$$
R_{i}^{\tau}\left(\hat{\mathbf{x}}_{i}\left(s_{i}\right), s\right)-\hat{\mathbf{u}}_{i}\left(s_{i}\right)=\left(1-\tau_{i}\right) R_{i}\left(\hat{\mathbf{x}}_{i}\left(s_{i}\right), s\right)+\tau_{i} R_{i}\left(x_{i}^{*}(s), s\right)-\mathbf{u}_{i}\left(s_{i}\right),
$$

where $\hat{\mathbf{x}}_{i}\left(s_{i}\right)=x_{i}^{e}\left(A\left(\hat{\mathbf{u}}_{i}\left(s_{i}\right)\right), s_{i}, \hat{\mathbf{u}}_{-i}\right)$ so that $R_{i}\left(\hat{\mathbf{x}}_{i}\left(s_{i}\right), s\right)$ is the ex-post joint surplus associated with the jointly interim efficient characteristics of the good given the signal vector $s=\left[s_{i}, s_{-i}\right]$ and $R_{i}\left(x_{i}^{*}(s), s\right)=v_{i}\left(x_{i}^{*}(s), s\right)+u\left(x_{i}^{*}(s)\right)$ is the jointly ex-post efficient surplus.

Suppose that the buyer chooses seller $i$ as the winning seller given the signal vector $s=\left[s_{i}, s_{-i}\right]$ in a separating monotone equilibrium $\left\{\mathbf{m}_{1}^{\tau}, \ldots, \mathbf{m}_{N}^{\tau}, \sigma^{\tau}\right\}$. The buyer receives the ex-post payoff of $\hat{\mathbf{u}}_{i}\left(s_{i}\right)$ for certain. However, the winning seller's ex-post payoff is $R_{i}\left(\hat{\mathbf{x}}_{i}\left(s_{i}\right), s\right)-\hat{\mathbf{u}}_{i}\left(s_{i}\right)$ with probability $1-\tau_{i}$ and $R_{i}\left(x_{i}^{*}(s), s\right)-\hat{\mathbf{u}}_{i}\left(s_{i}\right)$ with probability $\tau_{i}$, so that his expected ex-post payoff is $R_{i}^{\tau}\left(\hat{\mathbf{x}}_{i}\left(s_{i}\right), s\right)-\mathbf{u}_{i}\left(s_{i}\right)$. After the buyer selects the winning seller, the buyer and the winning seller may agree to renegotiate the contract if it is mutually beneficial given a signal vector $s$. If there is no contract that is mutually beneficial to the buyer and the winning seller given the signal vector, then the equilibrium is said to be jointly ex-post renegotiation-proof.

It is clear that $R_{i}\left(x_{i}^{*}(s), s\right) \geq R_{i}\left(\hat{\mathbf{x}}_{i}\left(s_{i}\right), s\right)$ for all $s=\left[s_{i}, s_{-i}\right]$ because $x_{i}^{*}(s)$ is jointly ex-post efficient and $\hat{\mathbf{x}}_{i}\left(s_{i}\right)$ is only jointly interim efficient. We assume that there exists $Z_{i} \subseteq[0,1]$ and $Z_{-i} \subseteq[0,1]^{N-1}$, each with positive measure such that (i) for all $s_{i} \in Z_{i}$ and all $s_{-i} \in Z_{-i}$,

$$
R_{i}\left(x_{i}^{*}\left(s_{i}, s_{-i}\right), s_{i}, s_{-i}\right)>R_{i}\left(\hat{\mathbf{x}}_{i}\left(s_{i}\right), s_{i}, s_{-i}\right) .
$$

and (ii) for all $s_{i} \in Z_{i}$,

$$
\operatorname{Pr}\left(A\left(\hat{\mathbf{u}}_{i}\left(s_{i}\right)\right) \mid s_{i}\right)>0
$$

If this assumption is not satisfied, then there is no sensible distinction between interdependent values and private values in equilibrium.

Proposition 1 Only the jointly ex-post efficient equilibrium, i.e., $\left\{\mathbf{m}_{1}^{\tau}, \ldots, \mathbf{m}_{N}^{\tau}, \sigma^{\tau}\right\}$ with $\tau_{i}=1$ for all $i$, is jointly ex-post renegotiation-proof. 
Joint ex-post renegotiation is a notion for examining whether the buyer and the winning seller can improve upon their renegotiation after the winning seller is determined. A seller may consider deviation from his menu even before the buyer chooses the winning seller. Given the multiplicity of continuation equilibrium, suppose that a separating equilibrium is based on a continuation equilibrium in which the buyer always chooses a jointly interim efficient contract from seller 1's menu upon accepting it but always chooses a jointly ex-post efficient contract from other sellers' menus upon accepting one of them. Given this particular continuation equilibrium, no sellers have incentives to deviate from their menus. However, if seller 1 believed, for example, that the buyer would in fact always choose a jointly ex-post efficient contract from his menu upon his deviation, he would deviate to submit a menu more aggressively in the sense that his new menu offers a higher payoff to the buyer than his original menu does. Not only does such a deviation show that equilibrium menus (and subsequently equilibrium contracts) in some equilibria are not robust to the possibility that the buyer would choose an alternative continuation equilibrium for her contract choice, but it also implies that the equilibrium prediction on how likely each seller would win is not ex-ante robust because more aggressive menu offers from seller 1 make it more likely for him to win and less likely for other sellers to win. In this sense, it is important to examine how ex-ante robust an equilibrium is to (sellers' beliefs on) the continuation equilibrium.

A separating monotone equilibrium $\left\{\mathbf{m}_{1}^{\tau}, \ldots, \mathbf{m}_{N}^{\tau}, \sigma^{\tau}\right\}$ is ex-ante robust ${ }^{13}$ to some alternative continuation equilibria if there exists a non-empty set of alternative continuation equilibria $C \subseteq \mathcal{C}$ with $\sigma^{\tau}=\left[\sigma_{1}^{\tau}, \ldots, \sigma_{N}^{\tau}\right] \notin C$ such that, for all $i$, a.e. $s_{i}$, all $m_{i}$, all $\sigma^{\prime}=\left[\sigma_{1}^{\prime}, \ldots, \sigma_{N}^{\prime}\right] \in C$

$$
V_{i}\left(\mathbf{m}_{i}^{\tau}\left(s_{i}\right), \mathbf{m}_{-i}^{\tau} \mid s_{i}, \sigma_{i}^{\tau}\right) \geq V_{i}\left(m_{i}, \mathbf{m}_{-i}^{\tau} \mid s_{i}, \sigma_{i}^{\prime}\right) .
$$

Fix a separating monotone equilibrium $\left\{\mathbf{m}_{1}^{\tau}, \ldots, \mathbf{m}_{N}^{\tau}, \sigma^{\tau}\right\}$. Suppose that seller $i$ with $s_{i}$ considers a deviation. He does not have incentives to deviate when he continues to hold the equilibrium belief on the continuation equilibrium, $\sigma^{\tau}$. Because there are multiple continuation equilibria, a seller's incentives for deviation differ across his beliefs on the continuation equilibrium. Even when seller $i$ with signal $s_{i}$ believes that the buyer might not follow the continuation equilibrium $\sigma^{\tau}$, he does not have an incentive to deviate as long as he believes the buyer would follow an alternative continuation equilibrium $\sigma^{\prime}$ in $C$ that satisfies (11).

As long as the buyer chooses a jointly ex-post efficient contract with positive probability in a separating monotone equilibrium, it is ex-ante robust to the set of continuation equilibria where she chooses a jointly ex-post efficient contract

\footnotetext{
${ }^{13}$ The notion of robustness follows the strong robustness adopted for competing mechanism games (Han 2007)
} 
less likely (i.e., with a lower probability). ${ }^{14}$ Theorem 3 shows that if a separating monotone equilibrium is based on the continuation equilibrium in which the buyer always chooses a jointly ex-post efficient contract from the winning seller's menu, it is ex-ante robust to every continuation equilibrium that the buyer chooses to follow for her contract choice.

Theorem 3 A separating monotone equilibrium $\left\{\mathbf{m}_{1}^{\tau}, \ldots, \mathbf{m}_{N}^{\tau}, \sigma^{\tau}\right\}$ with $\tau_{i}=1$ for all $i$ is ex-ante robust to every continuation equilibrium.

Proposition 1 and theorem 3 show that the jointly ex-post efficient equilibrium is both jointly ex-post renegotiation-proof and ex-ante robust to all continuation equilibria. Hence the equilibrium contract that the buyer chooses in the jointly ex-post efficient equilibrium is both ex-ante and ex-post stable and subsequently the jointly ex-post efficient equilibrium provides a stable prediction on how likely each seller would win procurement.

The jointly ex-post efficient separating monotone equilibrium is jointly expost renegotiation-proof regardless of the tie-breaking rule because it considers whether there exists a mutually beneficial alternative contract for the winning seller and the buyer after the winning seller is determined. While it, like any other separating monotone equilibria, is ex-ante robust to some alternative tiebreaking rules, it may not be ex-ante robust to every alternative tie-breaking rule under interdependent values. The tie-breaking rule does not have any bite if a deviating seller's menu has no possibility of ties with the other bidders' menus in terms of the buyer's maximum payoff that the menus can induce. However, it can affect a seller's incentive to deviate to a menu that could tie with the other sellers' menus with positive probability. Suppose that the buyer follows an alternative tie-breaking rule in which she chooses the deviating seller's menu for sure in "good news" events in which a lot of the other sellers' menus may tie with the deviating bidder's menu with positive probability. If the payoff upon always winning a tie conditional on "good news" events is sufficiently high and a seller believes that the buyer would follow such an alternative continuation equilibrium, he may have incentives to deviate to a menu with the possibility of ties. ${ }^{15}$

\footnotetext{
${ }^{14}$ If the buyer chooses a jointly ex-post efficient contract less likely, then a seller receives a lower interim payoff conditional on any payoff level that he is willing to give to the buyer. Therefore, an equilibrium is ex-ante robust to alternative continuation equilibria in which the buyer chooses a jointly ex-post efficient contract less likely.

${ }^{15}$ The existence of a monotone equilibrium under an alternative tie-breaking rule is yet to be established. The jointly ex-post efficient separating monotone equilibrium is robust to both all continuation equilibria and all tie-breaking rules only if every bidder's feasible menus have no possibility of ties with the other bidders' equilibrium menus. However, it is not known when this condition is satisfied.
} 


\section{Discussion}

Our approach is different from the mechanism design approach with the buyer's commitment to a decision rule or mechanism. We consider the situation in which the buyer cannot commit to a decision rule or mechanism for various reasons such as the complexity in designing a mechanism and implementing the decision rule in the mechanism or verifiability of messages. This paper examines the properties of equilibrium outcomes that can arise when sellers compete in menus in the firstprice menu auction without the buyer's commitment. In this sense, this paper is rather close to the growing literature on the decentralized market design via competition in menus (e.g. Bernheim and Whinston 1986, Dixit, Grossman and Helpman 1997), where bidders, conventionally called agents in the mechanism design literature, compete in offering menus to the decision maker who then simply chooses what she wants from a menu without committing to a decision rule.

Technically it is however very challenging to analyze equilibrium of the firstprice menu auction in general procurement environments with asymmetric sellers, interdependent values, and affiliated signals because it is difficult to establish the existence of a (monotone) equilibrium given the complexity of each seller's strategy space (i.e., the set of all possible menus of contracts). By extending Reny and Zamir's IRT-SCC and introducing TLS-SMC, this paper demonstrates that both the weakly single crossing condition and the weakly quasisupermodular condition in Reny (2011) are ensured at individually rational tieless bids. This leads us not only to establish the existence of separating monotone equilibria but also enables us to study the nature of equilibrium allocations in the asymmetric first-price menu auction under interdependent values in very general environments.

This paper considers the case with asymmetric sellers, interdependent values and affiliated signals. For this case, one can think of the generalized VCG mechanism (Dasgupta and Maskin 2010) or some variation of scoring auctions as the buyer's procurement mechanism, assuming that the buyer can commit to a decision rule or more generally mechanism. Dasgupta and Maskin (2000) argued that it is unrealistic to consider "direct revelation mechanisms" in which each seller directly reports a signal value because the mechanism designer is required to know the physical signal spaces available for bidders. Instead, their generalized VCG mechanism requires each bidder $i$ to submit a bidding function. For example, in a model with two bidders and a single indivisible object, each bidder submits a bidding function that specifies his bid as a function of the other bidder's bid. If a unique fixed point of bidding functions submitted by sellers exists, bids in the fixed point become bidders' bids and the bidder with the higher bid wins the object by paying the lower bid. The idea is that the equilibrium bidding function submitted by each bidder will depend on his signal in a way that the

submitted bidding functions induce the fixed point that is in fact the array of 
bidders' true valuations at each array of signals.

It is not known how to formulate the generalized VCG mechanism in procurement under interdependent values. While it requires formal analysis, my conjecture is that the generalized VCG mechanism could be considered in conjunction with the second scoring auction format. The buyer announces the scoring function that is the same as her payoff function, i.e., $u(x)-t$. Then, she invites sellers to submit their bidding functions. Each seller $i$ 's bidding function $\left(x_{i}, t_{i}\right)=b_{i}\left(x_{-i}, t_{-i}\right)$ specifies his contract as a function of the array of the other sellers' contracts. Given bidding functions $\left(b_{1}, \ldots, b_{N}\right)$, sellers' contracts are a fixed point of bidding functions, i.e.,

$$
\left[\left(x_{1}^{\circ}, t_{1}^{\circ}\right), \ldots\left(x_{N}^{\circ}, t_{N}^{\circ}\right)\right]=\left[b_{1}\left(x_{-1}^{\circ}, t_{-1}^{\circ}\right), \ldots, b_{N}\left(x_{-N}^{\circ}, t_{-N}^{\circ}\right)\right] .
$$

Then, the buyer assigns the score to each contract $\left(x_{i}^{\circ}, t_{i}^{\circ}\right)$. Seller $i$ with the highest score wins procurement with $\left(x_{i}^{\circ}, t_{i}^{\circ}\right)$. Seller $i$ then delivers the good with characteristics $x_{i}^{\circ}$ but the buyer's payment is adjusted to equate the winning seller's after-delivery score with the maximum score among losing bids.

It would be interesting to see under what conditions an equilibrium exists and whether or not an equilibrium induces a unique fixed point of jointly ex-post efficient contracts with the true cost of production, i.e., $\left(x_{i}^{\circ}, t_{i}^{\circ}\right)=\left(x_{i}^{*}(s), c_{i}\left(x_{i}^{*}(s), s\right)\right)$ for all $i$ and all $s=\left(s_{1}, \ldots, s_{N}\right)$. However, this generalized VCG mechanism relies on the buyer's commitment to the scoring function which needs to specify scores for all possible contracts just like as other scoring auctions do. Furthermore, as the number of sellers increases, the domain of the bidding function becomes exponentially complicated because it is the Cartesian products of the other sellers' whole contract spaces.

It would be also interesting to compare the buyer's expected payoffs across different auction formats (e.g., first-price menu auction, generalized VCG auction, and etc.) in the general environment with asymmetric bidders and interdependent values. This is possible in some simple cases. ${ }^{16}$ It is however very difficult to derive a general result on revenue comparison with asymmetric bidders and interdependent values. No results are established even in the auction environment for a single indivisible object with both asymmetric bidders and interdependent values. ${ }^{17}$ I leave this for future research.

\footnotetext{
${ }^{16}$ In Example 1, the first-price auction induces the buyer's expected payoff of $25 / 8=3 / 8 \times$ $(8-5)+1 / 8 \times(10-7)+1 / 8 \times(16-51 / 4)+3 / 8 \times(18-59 / 4)$. In the generalized VCG mechanism, the buyer's expected equilibrium payoff is $91 / 32=3 / 8 \times(8-6)+1 / 8 \times(10-7)+$ $1 / 8 \times(16-12)+3 / 8 \times(18-59 / 4)$. Therefore, the first-price menu auction generates a higher expected payoff for the buyer than the generalized VCG mechanism does.

${ }^{17}$ The well-known ranking results in the auction environment for a single indivisible object focus on either (i) asymmetric bidders with independent private values only (Kirkegaard 2012, Maskin and Riley 2000b) or (ii) symmetric bidders with interdependent values only (Milgrom and Weber 1982). However, Kirkegaard pointed out that there are plenty of small counter examples against the well-known ranking results.
} 


\section{APPENDIX}

Proof of Lemma 1. Following Reny and Zamir (2004), call a product of $N$ real intervals in $\mathbb{R}^{k}$ with $k \geq 1$ - each of which can be closed, open or half-open - a cell. For any cells $A$ and $A^{\prime}$ in $\mathbb{R}^{k}, A^{\prime} \geq A$ if the lower (upper) endpoint of each interval in the product defining $A$ is no greater than the lower (upper) endpoint of the corresponding interval in the product defining $A^{\prime}$. We can establish IRT-SCC in the modified auction by following the proof of Proposition 2.3 in Reny and Zamir (2004). Hence we provide only the proof of TLS-SMC below.

Consider any $\left(u_{i}, x_{i}\right)$ and $\left(u_{i}^{\prime}, x_{i}^{\prime}\right)$ such that $\operatorname{Pr}\left[u_{\circ}<\max _{j \neq i} \mathbf{u}_{j}\left(s_{j}\right)=u_{i}\right.$ or $\left.u_{i}^{\prime}\right]=0$ given any non-decreasing payoff bidding functions $\mathbf{u}_{-i}$. In this way, we can ensure that if seller $i$ 's payoff bid is $u_{i}$ or $u_{i}^{\prime}$, then the probability that seller $i$ 's payoff bid is the highest non-negative payoff bid is equal to the probability that seller $i$ 's payoff bid is the unique highest non-negative payoff bid. Because $f>0$ and the event that seller $i$ 's payoff bid is uniquely the highest depends only on the other sellers' signals, this event has positive probability if and only if it has positive probability on every $s_{i} \in[0,1]$. Hence we can respectively define the event that $u_{i}^{\prime}$ is a winning payoff bid and the event that $u_{i}$ is a winning payoff bid as $A^{\prime}=\left\{s_{-i} \in[0,1]^{N}: \max _{j \neq i} \mathbf{u}_{j}\left(s_{j}\right)<u_{i}^{\prime}\right\}$ and $A=\left\{s_{-i} \in[0,1]^{N}: \max _{j \neq i} \mathbf{u}_{j}\left(s_{j}\right)<u_{i}\right\}$. Without loss of generality, let $u_{i}^{\prime} \geq u_{i}$ and hence $u_{i} \vee u_{i}^{\prime}=u_{i}^{\prime}$ and $u_{i} \wedge u_{i}^{\prime}=u_{i}$. Because $u_{i}$ or $u_{i}^{\prime}$ is the unique payoff bids, the differences in seller $i$ 's interim payoffs are

$V_{i}\left(u_{i} \vee u_{i}^{\prime}, x_{i} \vee x_{i}^{\prime}, \mathbf{u}_{-i} \mid s_{i}\right)-V_{i}\left(u_{i}^{\prime}, x_{i}^{\prime}, \mathbf{u}_{-i} \mid s_{i}\right)=\operatorname{Pr}\left(A^{\prime} \mid s_{i}\right) \mathbb{E}\left[R_{i}^{\tau}\left(x_{i} \vee x_{i}^{\prime}, S\right)-R_{i}^{\tau}\left(x_{i}^{\prime}, S\right) \mid A^{\prime}, s_{i}\right]$, $V_{i}\left(u_{i}, x_{i}, \mathbf{u}_{-i} \mid s_{i}\right)-V_{i}\left(u_{i} \wedge u_{i}^{\prime}, x_{i} \wedge x_{i}^{\prime}, \mathbf{u}_{-i} \mid s_{i}\right)=\operatorname{Pr}\left(A \mid s_{i}\right) \mathbb{E}\left[R_{i}^{\tau}\left(x_{i}, S\right)-R_{i}^{\tau}\left(x_{i} \wedge x_{i}^{\prime}, S\right) \mid A, s_{i}\right]$.

Therefore, $V_{i}\left(u_{i} \vee u_{i}^{\prime}, x_{i} \vee x_{i}^{\prime}, \mathbf{u}_{-i} \mid s_{i}\right)-V_{i}\left(u_{i}^{\prime}, x_{i}^{\prime}, \mathbf{u}_{-i} \mid s_{i}\right)$ is the difference in seller $i$ 's interim payoffs associated with two action bids $x_{i} \vee x_{i}^{\prime}$ and $x_{i}^{\prime}$ given his payoff bid $u_{i}^{\prime} . V_{i}\left(u_{i}, x_{i}, \mathbf{u}_{-i} \mid s_{i}\right)-$ $V_{i}\left(u_{i} \wedge u_{i}^{\prime}, x_{i} \wedge x_{i}^{\prime}, \mathbf{u}_{-i} \mid s_{i}\right)$ is the difference in seller $i$ 's interim payoffs associated with two action bids $x_{i}$ and $x_{i} \wedge x_{i}^{\prime}$ given his payoff bid $u_{i}$. Because $\operatorname{Pr}\left(A^{\prime} \mid s_{i}\right) \geq \operatorname{Pr}\left(A \mid s_{i}\right)$, TLS-SMC holds if

$$
\mathbb{E}\left[R_{i}^{\tau}\left(x_{i} \vee x_{i}^{\prime}, S\right)-R_{i}^{\tau}\left(x_{i}^{\prime}, S\right) \mid A^{\prime}, s_{i}\right] \geq \mathbb{E}\left[R_{i}^{\tau}\left(x_{i}, S\right)-R_{i}^{\tau}\left(x_{i} \wedge x_{i}^{\prime}, S\right) \mid A, s_{i}\right]
$$

We first compare $\mathbb{E}\left[R_{i}^{\tau}\left(x_{i} \vee x_{i}^{\prime}, S\right)-R_{i}^{\tau}\left(x_{i}^{\prime}, S\right) \mid A^{\prime}, s_{i}\right]$ and $\mathbb{E}\left[R_{i}^{\tau}\left(x_{i} \vee x_{i}^{\prime}, S\right)-R_{i}^{\tau}\left(x_{i}^{\prime}, S\right) \mid A, s_{i}\right]$. Because $u_{i}^{\prime} \geq u_{i}$ and the other sellers employ non-decreasing strategies, both $A^{\prime}$ and $A$ are products of cells with zero lower endpoints, but the upper endpoint of the cell for each seller $j$ 's signal in $A^{\prime}$ is no less than the upper endpoint of the corresponding cell in $A$. Furthermore, $R_{i}^{\tau}\left(x_{i} \vee x_{i}^{\prime}, s\right)-R_{i}^{\tau}\left(x_{i}^{\prime}, s\right)$ is non-decreasing in $s_{-i}$. Therefore, we can directly invoke Theorem 5 in Milgrom and Weber (1982) so that

$$
\mathbb{E}\left[R_{i}^{\tau}\left(x_{i} \vee x_{i}^{\prime}, S\right)-R_{i}^{\tau}\left(x_{i}^{\prime}, S\right) \mid A^{\prime}, s_{i}\right] \geq \mathbb{E}\left[R_{i}^{\tau}\left(x_{i} \vee x_{i}^{\prime}, S\right)-R_{i}^{\tau}\left(x_{i}^{\prime}, S\right) \mid A, s_{i}\right] .
$$

Consider $\mathbb{E}\left[R_{i}^{\tau}\left(x_{i} \vee x_{i}^{\prime}, S\right)-R_{i}^{\tau}\left(x_{i}^{\prime}, S\right) \mid A, s_{i}\right]$ and $\mathbb{E}\left[R_{i}^{\tau}\left(x_{i}, S\right)-R_{i}^{\tau}\left(x_{i} \wedge x_{i}^{\prime}, S\right) \mid A, s_{i}\right]$. Because $R_{i}^{\tau}$ is supermodular at each $s$, it is clear that

$$
\mathbb{E}\left[R_{i}^{\tau}\left(x_{i} \vee x_{i}^{\prime}, S\right)-R_{i}^{\tau}\left(x_{i}^{\prime}, S\right) \mid A, s_{i}\right] \geq \mathbb{E}\left[R_{i}^{\tau}\left(x_{i}, S\right)-R_{i}^{\tau}\left(x_{i} \wedge x_{i}^{\prime}, S\right) \mid A, s_{i}\right] .
$$

Combining (13) and (14) yields (12) and hence TLS-SMC holds.

Proof of Lemma 2. First, we show that the set of each seller $i$ 's best replies is monotone. Consider $B_{i}\left(s_{i}\right)$ and $B_{i}\left(s_{i}^{\prime}\right)$ for seller $i$, one under $s_{i}$ and the other with $s_{i}^{\prime}$ such that $s_{i}^{\prime} \geq s_{i} \geq \varepsilon$ given the other sellers' monotone strategies. For Reny's monotonicity of the set of seller $i$ 's 
best replies, it is sufficient to show that whenever a best reply $\left(u_{i}, x_{i}\right)$ in $B_{i}\left(s_{i}\right)$ is not $\left(u_{\circ}, x_{\circ}\right)$, then $\left(u_{i} \vee u_{i}^{\prime}, x_{i} \vee x_{i}^{\prime}\right) \in B_{i}\left(s_{i}^{\prime}\right)$ for any $\left(u_{i}^{\prime}, x_{i}^{\prime}\right) \in B_{i}\left(s_{i}^{\prime}\right)$.

Suppose that $\left(u_{i}^{\prime}, x_{i}^{\prime}\right) \neq\left(u_{\circ}, x_{\circ}\right)$. Because $\left(u_{i}, x_{i}\right) \neq\left(u_{\circ}, x_{\circ}\right)$ is in $B_{i}\left(s_{i}\right)$ and $\left(u_{\circ}, x_{\circ}\right)$ is always feasible, we have

$$
V_{i}\left(u_{i}, x_{i}, \mathbf{u}_{-i} \mid s_{i}\right) \geq V_{i}\left(u_{i} \wedge u_{i}^{\prime}, x_{i} \wedge x_{i}^{\prime}, \mathbf{u}_{-i} \mid s_{i}\right) .
$$

Note that both $\left(u_{i}, x_{i}\right)$ and $\left(u_{i}^{\prime}, x_{i}^{\prime}\right)$ are not $\left(u_{\circ}, x_{\circ}\right)$. Because no two payoff bid sets have any serious bid in common, $\operatorname{Pr}\left[u_{\circ}<\max _{j \neq i} \mathbf{u}_{j}\left(s_{j}\right)=u_{i}\right.$ or $\left.u_{i}^{\prime}\right]=0$. Furthermore, $\left(u_{i}, x_{i}\right)$ is individually rational because it is in $B_{i}\left(s_{i}\right)$. Invoking (8) in IRT-SCC, (15) yields

$$
V_{i}\left(u_{i}, x_{i}, \mathbf{u}_{-i} \mid s_{i}^{\prime}\right) \geq V_{i}\left(u_{i} \wedge u_{i}^{\prime}, x_{i} \wedge x_{i}^{\prime}, \mathbf{u}_{-i} \mid s_{i}^{\prime}\right) .
$$

Applying (7) from TLS-SMC, (16) implies

$$
V_{i}\left(u_{i} \vee u_{i}^{\prime}, x_{i} \vee x_{i}^{\prime}, \mathbf{u}_{-i} \mid s_{i}^{\prime}\right) \geq V_{i}\left(u_{i}^{\prime}, x_{i}^{\prime}, \mathbf{u}_{-i} \mid s_{i}^{\prime}\right)
$$

so that $\left(u_{i} \vee u_{i}^{\prime}, x_{i} \vee x_{i}^{\prime}\right)$ is in $B_{i}\left(s_{i}^{\prime}\right)$.

Suppose that $\left(u_{i}^{\prime}, x_{i}^{\prime}\right)=\left(u_{\circ}, x_{\circ}\right)$. The interim payoff for seller $i$ with signal $s_{i}$, associated with $\left(u_{i}, x_{i}\right) \in B_{i}\left(s_{i}\right)$ such that $\left(u_{i}, x_{i}\right) \neq\left(u_{\circ}, x_{\circ}\right)$, is

$$
V_{i}\left(u_{i}, x_{i}, \mathbf{u}_{-i} \mid s_{i}\right)=\operatorname{Pr}\left(A\left(u_{i}\right) \mid s_{i}\right) \mathbb{E}\left[R_{i}^{\tau}\left(x_{i}, S\right)-u_{i} \mid A\left(u_{i}\right), s_{i}\right] \geq 0,
$$

where the inequality holds because $\left(u_{i}, x_{i}\right) \in B_{i}\left(s_{i}\right)$, the losing bid $\left(u_{\circ}, x_{\circ}\right)$ is always feasible for seller $i$, and $u_{i} \neq u_{\circ}$ does not tie with the other sellers' payoff bids. Because every other seller $j$ submits $\left(u_{\circ}, x_{\circ}\right)$ when his signal is in $[0, \varepsilon)$ and the joint density of signals is strictly positive on $[0,1]^{N},\left(u_{i}, x_{i}\right) \neq\left(u_{\circ}, x_{\circ}\right)$ wins the procurement with positive probability, i.e., $\operatorname{Pr}\left(A\left(u_{i}\right) \mid s_{i}\right)>0$, for any $s_{i}$. It follows that (18) implies

$$
\mathbb{E}\left[R_{i}^{\tau}\left(x_{i}, S\right)-u_{i} \mid A\left(u_{i}\right), s_{i}\right] \geq 0 .
$$

Because $R_{i}^{\tau}\left(x_{i}, s\right)-u_{i}$ is non-decreasing in $s_{i}$, Theorem 5 in Milgrom and Weber leads (19) to

$$
\mathbb{E}\left[R_{i}^{\tau}\left(x_{i}, S\right)-u_{i} \mid A\left(u_{i}\right), s_{i}^{\prime}\right] \geq 0 .
$$

From (20), we have

$$
V_{i}\left(u_{i}, x_{i}, \mathbf{u}_{-i} \mid s_{i}^{\prime}\right)=\operatorname{Pr}\left(A\left(u_{i}\right) \mid s_{i}^{\prime}\right) \mathbb{E}\left[R_{i}^{\tau}(x, S)-u \mid A\left(u_{i}\right), s_{i}^{\prime}\right] \geq 0 .
$$

Because $\left(u_{i}^{\prime}, x_{i}^{\prime}\right)=\left(u_{\circ}, x_{\circ}\right) \in B_{i}\left(s_{i}^{\prime}\right),(21)$ implies that

$$
V_{i}\left(u_{i} \vee u_{i}^{\prime}, x_{i} \vee x_{i}^{\prime}, \mathbf{u}_{-i} \mid s_{i}^{\prime}\right)=V_{i}\left(u_{i}, x_{i}, \mathbf{u}_{-i} \mid s_{i}^{\prime}\right) \geq V_{i}\left(u_{i}^{\prime}, x_{i}^{\prime}, \mathbf{u}_{-i} \mid s_{i}^{\prime}\right)=0
$$

so that $\left(u_{i} \vee u_{i}^{\prime}, x_{i} \vee x_{i}^{\prime}\right)=\left(u_{i}, x_{i}\right) \in B_{i}\left(s_{i}^{\prime}\right)$

(17) and (22) show that whenever a best reply $\left(u_{i}, x_{i}\right)$ in $B_{i}\left(s_{i}\right)$ is not $\left(u_{\circ}, x_{\circ}\right)$, then $\left(u_{i} \vee\right.$ $\left.u_{i}^{\prime}, x_{i} \vee x_{i}^{\prime}\right) \in B_{i}\left(s_{i}^{\prime}\right)$ for any $\left(u_{i}^{\prime}, x_{i}^{\prime}\right) \in B_{i}\left(s_{i}^{\prime}\right)$ and any $s_{i}^{\prime}$ and $s_{i}$ such that $s_{i}^{\prime} \geq s_{i} \geq \varepsilon$. Therefore, Reny's monotonicity of the set of seller $i$ 's best replies goes through.

Examine the join-closedness of $B_{i}\left(s_{i}\right)$. Reny's monotonicity of the set of seller $i$ 's best replies states that if $s_{i}^{\prime} \geq s_{i},\left(u_{i}, x_{i}\right) \in B_{i}\left(s_{i}\right)$ and $\left(u_{i}^{\prime}, x_{i}^{\prime}\right) \in B_{i}\left(s_{i}^{\prime}\right)$ imply $\left(u_{i} \vee u_{i}^{\prime}, x_{i} \vee x_{i}^{\prime}\right) \in B_{i}\left(s_{i}^{\prime}\right)$. Setting $s_{i}^{\prime}=s_{i}$ yields that $\left(u_{i}, x_{i}\right) \in B_{i}\left(s_{i}\right)$ and $\left(u_{i}^{\prime}, x_{i}^{\prime}\right) \in B_{i}\left(s_{i}\right)$ imply $\left(u_{i} \vee u_{i}^{\prime}, x_{i} \vee x_{i}^{\prime}\right) \in B_{i}\left(s_{i}\right)$. Therefore, $B_{i}\left(s_{i}\right)$ is join-closed. 
Examine the non-emptiness of $B_{i}\left(s_{i}\right)$. A characteristics bid $x_{i}$ that seller $i$ submits along with a payoff bid $u_{i}$ does not affect the winning event, and it is chosen with probability $\tau_{i}$ conditional on seller $i$ winning the procurement. Furthermore, the buyer takes the monetary payment $t_{i}=u\left(x_{i}\right)-u_{i}$ given, in this case, seller $i$ 's bid $\left(u_{i}, x_{i}\right)$. If seller $i$ with signal $s_{i}$ submits a payoff bid $u_{i}$ for any $u_{i} \in U_{i}^{n}$, it is optimal for him to submit the jointly interim efficient characteristics $x_{i}^{e}\left(A\left(u_{i}\right), s_{i}, \mathbf{u}_{-i}\right)$ in $X_{i}^{e}\left(A\left(u_{i}\right), s_{i}, \mathbf{u}_{-i}\right)$, as defined in (2). Note that $X_{i}^{e}\left(A\left(u_{i}\right), s_{i}, \mathbf{u}_{-i}\right)$ is non-empty. Because $U_{i}^{n}$ is a finite set and $V_{i}\left(u_{i}, x_{i}^{e}\left(A\left(u_{i}\right), s_{i}, \mathbf{u}_{-i}\right), \mathbf{u}_{-i} \mid s_{i}\right)$ is bounded, there exists a payoff bid in $U_{i}^{n}$ that maximizes $V_{i}\left(u_{i}, x_{i}^{e}\left(A\left(u_{i}\right), s_{i}, \mathbf{u}_{-i}\right), \mathbf{u}_{-i} \mid s_{i}\right)$. Therefore, $B_{i}\left(s_{i}\right)$ is non-empty.

Finally, $U_{i}^{n}$ is a finite set and a lattice. This property and assumption 1 lead $U_{i}^{n} \times \mathbb{X}$ to satisfy G.3 and G.4 in Reny (2011). Assumption 3.(i) and 2.(i)-(ii) satisfy G.1, G.2, and G.5; therefore, Reny's conditions (G.1-G.5) on players' actions, payoff functions and types are all satisfied. The existence of a monotone equilibrium is established by Theorem 4.1 in Reny (2011).

Proof of Theorem 1. The existence of a monotone equilibrium in the modified auction with finite sets of payoff bids is established in Lemma 2. The proof of Theorem 1 follows part 2 of the proof of Theorem 2.1 in Reny and Zamir (2004) to show that the limit of the modified auctions with finite sets of payoff bids has a monotone equilibrium without restrictions on the sets of payoff bids. For $n=1,2, \ldots$, let $G^{n}$ denote the modified auction in which seller $i$ 's finite set of payoff bids is denoted by $U_{i}^{n}$ and hence the set of payoff bids and actions is $U_{i}^{n} \times \mathbb{X}$. We assume that $U_{i}^{n-1} \subseteq U_{i}^{n}$ and that $\bigcup_{n} U_{i}^{n}$ is dense in $U_{i}$. Let $\left(\mathbf{u}_{i}^{n}, \mathbf{x}_{i}^{n}\right)$ be seller $i$ 's equilibrium strategy in the modified auction $G^{n}$.

Consider the limit strategies. Because $R^{\tau}(\cdot, s)$ is bounded above at each $s \in[0,1]^{N}$ with Assumption 2.(iii), there exists $\tilde{u}>0$ such that $R^{\tau}(x, s)-\tilde{u}<0$ for all $(x, s) \in \mathbb{X} \times[0,1]^{N}$. Therefore, $\mathbf{u}_{i}^{n}(\cdot)$ is bounded above by $\tilde{u}$ and below by $u_{\circ}$, and it is also non-decreasing in $s_{i}$. By Helley's Selection Theorem, we then have that $\mathbf{u}_{i}^{n}\left(s_{i}\right) \rightarrow \hat{\mathbf{u}}_{i}\left(s_{i}\right)$ for a.e. $s_{i} \in[0,1]$, where $\hat{\mathbf{u}}_{i}(\cdot)$ is a non-decreasing function.

Because $\mathbf{x}_{i}^{n}(\cdot)$ is non-decreasing in $s_{i}$, and the conditions G.1-G.3 in Reny (2011), a generalized Helley's selection Theorem (Lemma A.10 in Reny 2011) implies that $\mathbf{x}_{i}^{n}\left(s_{i}\right) \rightarrow \hat{\mathbf{x}}_{i}\left(s_{i}\right)$ for a.e. $s_{i} \in[0,1]$, where $\hat{\mathbf{x}}_{i}(\cdot)$ is a non-decreasing function. We shall prove that $\left\{\left(\hat{\mathbf{u}}_{1}, \hat{\mathbf{x}}_{1}\right), \ldots,\left(\hat{\mathbf{u}}_{N}, \hat{\mathbf{x}}_{N}\right)\right\}$ is a monotone equilibrium in the modified auction. Ties should be carefully handled in two fronts.

The proof consists of two parts. In part 1, we show that, given the limit bidding functions $\hat{\mathbf{u}}_{-i}$ of the other sellers, seller $i$ 's interim payoff associated with any bid $\left(u_{i}, x_{i}\right)$ can be approximated arbitrarily well or he can improve upon his payoff by slightly increasing his payoff bid, given the same action bid $x_{i}$, that does not tie the other sellers' payoff bids with probability one. This is illustrated in (23).

In part 2, we are concerned that the possibility of ties may lead the limiting payoffs to differ from the payoffs at the limit strategies. It is shown that the probability that, under $\hat{\mathbf{u}}$, two or more sellers simultaneously submit the highest payoff bid above $u_{\circ}$ is zero so that the limiting payoff for seller $i$ with $s_{i}$ is always obtained by employing the limit bids $\left(\hat{\mathbf{u}}_{i}\left(s_{i}\right), \hat{\mathbf{x}}_{i}\left(s_{i}\right)\right)$ given the other sellers' limit bidding functions, $\hat{\mathbf{u}}_{-i}$. Part 2 can be established by following the proof of part 2 in Theorem 2.1 in Reny and Zamir. Hence we provide only the proof of part 1 below.

Given the other sellers' non-decreasing payoff bidding functions $\hat{\mathbf{u}}_{-i}$, let $A\left(u_{i}\right)=\left\{s_{-i} \in\right.$ $\left.[0,1]^{N-1}: \max _{j \neq i} \hat{\mathbf{u}}_{j}\left(s_{j}\right) \leq u_{i}\right\}$. Suppose that seller $i$ with $s_{i}$ submits a bid $\left(u_{i}, x_{i}\right)$ such that 
$V_{i}\left(u_{i}, x_{i}, \hat{\mathbf{u}}_{-i} \mid s_{i}\right) \geq 0$. Let $\mathbb{E}\left[\cdot \mid s_{i}, H_{i}\right]=0$ if $\operatorname{Pr}\left(H_{i} \mid s_{i}\right)=0$. Then, the following relations hold:

$$
\begin{aligned}
0 & \leq V_{i}\left(u_{i}, x_{i}, \hat{\mathbf{u}}_{-i} \mid s_{i}\right) \\
& =\operatorname{Pr}\left(A\left(u_{i}\right) \mid s_{i}\right) \mathbb{E}\left[\left(R_{i}^{\tau}\left(x_{i}, S\right)-u_{i}\right) \lambda_{i}\left(u_{i}, \hat{\mathbf{u}}_{-i}\left(S_{-i}\right)\right) \mid A\left(u_{i}\right), s_{i}\right] \\
& \leq \operatorname{Pr}\left(A\left(u_{i}\right) \mid s_{i}\right) \mathbb{E}\left[R_{i}^{\tau}\left(x_{i}, S\right)-u_{i} \mid A\left(u_{i}\right), s_{i}\right] \mathbb{E}\left[\lambda_{i}\left(u_{i}, \hat{\mathbf{u}}_{-i}\left(S_{-i}\right)\right) \mid A\left(u_{i}\right), s_{i}\right] \\
& \leq \operatorname{Pr}\left(A\left(u_{i}\right) \mid s_{i}\right) \mathbb{E}\left[R_{i}^{\tau}\left(x_{i}, S\right)-u_{i} \mid A\left(u_{i}\right), s_{i}\right] \\
& =\lim _{u_{i}^{\prime} \downarrow u_{i}} V_{i}\left(u_{i}^{\prime}, x_{i}, \hat{\mathbf{u}}_{-i} \mid s_{i}\right),
\end{aligned}
$$

where the inequality on the third line follows from Theorem 23 in Milgrom and Weber (1982) because both $R_{i}^{\tau}\left(x_{i}, s\right)-u_{i}$ and $1-\lambda_{i}\left(u_{i}, \hat{\mathbf{u}}_{-i}\left(s_{-i}\right)\right)$ are non-decreasing in $s_{-i}$ given the uniform tie-breaking rule. The inequality on the fourth line holds because

$$
\operatorname{Pr}\left(A\left(u_{i}\right) \mid s_{i}\right)>0 \Longrightarrow 0<\mathbb{E}\left[\lambda_{i}\left(u_{i}, \hat{\mathbf{u}}_{-i}\left(S_{-i}\right)\right) \mid A\left(u_{i}\right), s_{i}\right] \leq 1
$$

given the uniform tie-breaking rule. The equality on the fifth line holds because seller $i$ can approximate his payoff arbitrarily well by submitting a slightly higher payoff bid $u_{i}^{\prime}$, with the same characteristics bid $x_{i}$, that is never one of the at most countably many mass points of $\max _{j \neq i} \hat{\mathbf{u}}_{j}\left(S_{j}\right)$.

Proof of Theorem 2. Fix a monotone equilibrium $\left\{\left(\hat{\mathbf{u}}_{1}, \hat{\mathbf{x}}_{1}\right), \ldots,\left(\hat{\mathbf{u}}_{N}, \hat{\mathbf{x}}_{N}\right)\right\}$ in the modified auction for any given $\tau=\left[\tau_{1}, \ldots, \tau_{N}\right] \in[0,1]^{N}$. For any menu $m_{i}$ in the the first-price menu auction, let $\tilde{u}_{i}\left(m_{i}\right)$ be the maximum payoff level that the buyer can achieve by choosing $m_{i}$. Let each seller $i$ choose a menu $\mathbf{m}_{i}^{\tau}\left(s_{i}\right)$ that satisfies (i) $\tilde{u}_{i}\left(\mathbf{m}_{i}^{\tau}\left(s_{i}\right)\right)=\hat{\mathbf{u}}_{i}\left(s_{i}\right)$ for all $s_{i} \in[0,1]$, (ii) $\left(x_{i}^{*}(s), u\left(x_{i}^{*}(s)\right)-\hat{\mathbf{u}}_{i}\left(s_{i}\right)\right) \in D\left(m_{i}\right)$ for all $s \in[0,1]^{N}$, (iii) $\left(\hat{\mathbf{x}}_{i}\left(s_{i}\right), u\left(\hat{\mathbf{x}}_{i}\left(s_{i}\right)\right)-\hat{\mathbf{u}}_{i}\left(s_{i}\right)\right) \in D\left(m_{i}\right)$ for all $s_{i} \in[0,1]$, and (iv) $\mathbf{m}_{i}^{\tau}\left(s_{i}\right) \neq \mathbf{m}_{i}^{\tau}\left(s_{i}^{\prime}\right)$ if $s_{i} \neq s_{i}^{\prime}$. Once the buyer accepts seller $i$ 's menu $m_{i}$, given the other sellers' menu strategies $\mathbf{m}_{-i}^{\tau}$, she chooses a contract from $m_{i}$ in the following manner:

1. If $m_{i}=\mathbf{m}_{i}^{\tau}\left(s_{i}\right)$ for some $s_{i}$

$$
\sigma_{i}^{\tau}\left(m_{i}, \mathbf{m}_{-i}^{\tau}\left(s_{-i}\right)\right)=\left\{\begin{array}{cc}
\left(\hat{\mathbf{x}}_{i}\left(s_{i}\right), u\left(\hat{\mathbf{x}}_{i}\left(s_{i}\right)\right)-\hat{\mathbf{u}}_{i}\left(s_{i}\right)\right) \in D\left(m_{i}\right) & \text { with prob } 1-\tau_{i} \\
\left(x_{i}^{*}(s), u\left(x_{i}^{*}(s)\right)-\hat{\mathbf{u}}_{i}\left(s_{i}\right)\right) \in D\left(m_{i}\right) & \text { with prob. } \tau_{i}
\end{array},\right.
$$

2. otherwise, $\sigma_{i}^{\tau}\left(m_{i}, \mathbf{m}_{-i}^{\tau}\left(s_{-i}\right)\right)=\left(x_{i}, u\left(x_{i}\right)-\tilde{u}_{i}\left(m_{i}\right)\right)$ with prob. one, where $x$ is some arbitrary characteristics such that $\left(x_{i}, u\left(x_{i}\right)-\tilde{u}_{i}\left(m_{i}\right)\right) \in D\left(m_{i}\right)$.

Because $D\left(m_{i}\right)$ is the set of optimal contracts for the buyer once she accepts $m_{i}, \sigma^{\tau}=$ $\left[\sigma_{1}^{\tau}, \ldots, \sigma_{N}^{\tau}\right]$ characterized by 1 and 2 is a continuation equilibrium. Suppose that seller $i$ chooses a strategy $\mathbf{m}_{i}^{\tau}$. When his signal is $s_{i}$ and he offers the menu $\mathbf{m}_{i}^{\tau}\left(s_{i}\right)$, his interim payoff is

$$
\begin{aligned}
& V_{i}\left(\mathbf{m}_{i}^{\tau}\left(s_{i}\right), \mathbf{m}_{-i}^{\tau} \mid s_{i}, \sigma_{i}^{\tau}\right)= \\
& \left(1-\tau_{i}\right) \operatorname{Pr}\left(A\left(\hat{\mathbf{u}}_{i}\left(s_{i}\right)\right) \mid s_{i}\right) \mathbb{E}\left[\left(R_{i}\left(\hat{\mathbf{x}}_{i}\left(S_{i}\right), S\right)-\hat{\mathbf{u}}_{i}\left(S_{i}\right)\right) \lambda_{i}(\hat{\mathbf{u}}(S)) \mid A\left(\hat{\mathbf{u}}_{i}\left(s_{i}\right)\right), s_{i}\right]+ \\
& \tau_{i} \operatorname{Pr}\left(A\left(\hat{\mathbf{u}}_{i}\left(s_{i}\right)\right) \mid s_{i}\right) \mathbb{E}\left[\left(R_{i}\left(x_{i}^{*}(S), S\right)-\hat{\mathbf{u}}_{i}\left(S_{i}\right)\right) \lambda_{i}(\hat{\mathbf{u}}(S)) \mid A\left(\hat{\mathbf{u}}_{i}\left(s_{i}\right)\right), s_{i}\right]= \\
& V_{i}\left(\hat{\mathbf{u}}_{i}\left(s_{i}\right), \hat{\mathbf{x}}_{i}\left(s_{i}\right), \hat{\mathbf{u}}_{-i} \mid s_{i}\right)
\end{aligned}
$$

There are two types of deviations in the first-price menu auction. First of all, consider that seller $i$ deviates to a menu $\mathbf{m}_{i}^{\tau}\left(s_{i}^{\prime}\right)$ for some $s_{i}^{\prime}\left(s_{i}^{\prime} \neq s_{i}\right)$. When seller $i$ with $s_{i}$ deviates to the 
menu $\mathbf{m}_{i}^{\tau}\left(s_{i}^{\prime}\right)$, the buyer believes that his signal is $s_{i}^{\prime}$. Once she accepts the menu $\mathbf{m}_{i}^{\tau}\left(s_{i}^{\prime}\right)$, she will take the characteristics $\hat{\mathbf{x}}_{i}\left(s_{i}^{\prime}\right)$ with probability $1-\tau_{i}$ and the characteristics $x_{i}^{*}\left(s_{i}^{\prime}, s_{-i}\right)$ with probability $\tau_{i}$ when the other sellers' menus are $\mathbf{m}_{-i}^{\tau}\left(s_{-i}\right)$. Therefore, seller $i$ 's interim payoff $V_{i}\left(\mathbf{m}_{i}^{\tau}\left(s_{i}^{\prime}\right), \mathbf{m}_{-i}^{\tau} \mid s_{i}, \sigma_{i}^{\tau}\right)$ becomes

$$
\begin{aligned}
& V_{i}\left(\mathbf{m}_{i}^{\tau}\left(s_{i}^{\prime}\right), \mathbf{m}_{-i}^{\tau} \mid s_{i}, \sigma_{i}^{\tau}\right)=\left(1-\tau_{i}\right) \operatorname{Pr}\left(A\left(\hat{\mathbf{u}}_{i}\left(s_{i}^{\prime}\right)\right) \mid s_{i}\right) \times \\
& \mathbb{E}\left[\left(R_{i}\left(\hat{\mathbf{x}}_{i}\left(s_{i}^{\prime}\right), S\right)-\hat{\mathbf{u}}_{i}\left(s_{i}^{\prime}\right)\right) \lambda_{i}\left(\hat{\mathbf{u}}_{i}\left(s_{i}^{\prime}\right), \hat{\mathbf{u}}_{-i}\left(S_{-i}\right)\right) \mid A\left(\hat{\mathbf{u}}_{i}\left(s_{i}^{\prime}\right)\right), s_{i}\right]+ \\
& \quad \tau_{i} \operatorname{Pr}\left(A\left(\hat{\mathbf{u}}_{i}\left(s_{i}^{\prime}\right) \mid s_{i}\right) \times\right. \\
& \mathbb{E}\left[\left(R_{i}\left(x_{i}^{*}\left(s_{i}^{\prime}, S_{-i}\right), S\right)-\hat{\mathbf{u}}_{i}\left(s_{i}^{\prime}\right)\right) \lambda_{i}\left(\hat{\mathbf{u}}_{i}\left(s_{i}^{\prime}\right), \hat{\mathbf{u}}_{-i}\left(S_{-i}\right)\right) \mid A\left(\hat{\mathbf{u}}_{i}\left(s_{i}^{\prime}\right)\right), s_{i}\right] .
\end{aligned}
$$

This interim payoff $V_{i}\left(\mathbf{m}_{i}^{\tau}\left(s_{i}^{\prime}\right), \mathbf{m}_{-i}^{\tau} \mid s_{i}, \sigma_{i}^{\tau}\right)$ satisfies

$$
\begin{gathered}
V_{i}\left(\mathbf{m}_{i}^{\tau}\left(s_{i}^{\prime}\right), \mathbf{m}_{-i}^{\tau} \mid s_{i}, \sigma_{i}^{\tau}\right) \leq\left(1-\tau_{i}\right) \operatorname{Pr}\left(A\left(\hat{\mathbf{u}}_{i}\left(s_{i}^{\prime}\right)\right) \mid s_{i}\right) \times \\
\mathbb{E}\left[\left(R_{i}\left(x_{i}^{e}\left(\hat{\mathbf{u}}_{i}\left(s_{i}^{\prime}\right), s_{i}, \hat{\mathbf{u}}_{-i}\right), S\right)-\hat{\mathbf{u}}_{i}\left(s_{i}^{\prime}\right)\right) \lambda_{i}\left(\hat{\mathbf{u}}_{i}\left(s_{i}^{\prime}\right), \hat{\mathbf{u}}_{-i}\left(S_{-i}\right)\right) \mid A\left(\hat{\mathbf{u}}_{i}\left(s_{i}^{\prime}\right)\right), s_{i}\right]+ \\
\tau_{i} \operatorname{Pr}\left(A\left(\hat{\mathbf{u}}_{i}\left(s_{i}^{\prime}\right) \mid s_{i}\right) \times\right. \\
\mathbb{E}\left[\left(R_{i}\left(x_{i}^{*}(S), S\right)-\hat{\mathbf{u}}_{i}\left(s_{i}^{\prime}\right)\right) \lambda_{i}\left(\hat{\mathbf{u}}_{i}\left(s_{i}^{\prime}\right), \hat{\mathbf{u}}_{-i}\left(S_{-i}\right)\right) \mid A\left(\hat{\mathbf{u}}_{i}\left(s_{i}^{\prime}\right)\right), s_{i}\right]= \\
V_{i}\left(\hat{\mathbf{u}}_{i}\left(s_{i}^{\prime}\right), x_{i}^{e}\left(\hat{\mathbf{u}}_{i}\left(s_{i}^{\prime}\right), s_{i}, \hat{\mathbf{u}}_{-i}\right), \hat{\mathbf{u}}_{-i} \mid s_{i}\right) .
\end{gathered}
$$

We show why (26) holds. Note that the equality in (26) follows the definition of the interim payoff for seller $i$ with $s_{i}$, i.e., $V_{i}\left(\hat{\mathbf{u}}_{i}\left(s_{i}^{\prime}\right), x_{i}^{e}\left(\hat{\mathbf{u}}_{i}\left(s_{i}^{\prime}\right), s_{i}, \hat{\mathbf{u}}_{-i}\right), \hat{\mathbf{u}}_{-i} \mid s_{i}\right)$, in the modified auction when he deviates to submit the bid $\left(\hat{\mathbf{u}}_{i}\left(s_{i}^{\prime}\right), x_{i}^{e}\left(\hat{\mathbf{u}}_{i}\left(s_{i}^{\prime}\right), s_{i}, \hat{\mathbf{u}}_{-i}\right)\right)$. Consider the inequality in (26). The winning event associated with the bid $\left(\hat{\mathbf{u}}_{i}\left(s_{i}^{\prime}\right), x_{i}^{e}\left(\hat{\mathbf{u}}_{i}\left(s_{i}^{\prime}\right), s_{i}, \hat{\mathbf{u}}_{-i}\right)\right)$ in the modified auction and the winning event associated with $\mathbf{m}_{i}^{\tau}\left(s_{i}^{\prime}\right)$ in the the first-price menu auction are both $A\left(\hat{\mathbf{u}}_{i}\left(s_{i}^{\prime}\right)\right)$. When seller $i$ of signal $s_{i}$ deviates to $\mathbf{m}_{i}^{\tau}\left(s_{i}^{\prime}\right)$ in the the firstprice menu auction, the buyer chooses $\left(\hat{\mathbf{x}}_{i}\left(s_{i}^{\prime}\right), u\left(\hat{\mathbf{x}}_{i}\left(s_{i}^{\prime}\right)\right)-\hat{\mathbf{u}}_{i}\left(s_{i}^{\prime}\right)\right)$ with probability $1-\tau_{i}$ but $\left(x_{i}^{*}\left(s_{i}^{\prime}, s_{-i}\right), u\left(x_{i}^{*}\left(s_{i}^{\prime}, s_{-i}\right)\right)-\hat{\mathbf{u}}_{i}\left(s_{i}^{\prime}\right)\right)$ at each $s_{-i}$ with probability $\tau_{i}$ as if seller $i$ 's signal was $s_{i}^{\prime}$. However, when seller $i$ of signal $s_{i}$ deviates to the bid $\left(\hat{\mathbf{u}}_{i}\left(s_{i}^{\prime}\right), x_{i}^{e}\left(\hat{\mathbf{u}}_{i}\left(s_{i}^{\prime}\right), s_{i}, \hat{\mathbf{u}}_{-i}\right)\right)$ in the modified auction, the buyer takes the correct jointly interim efficient contract

$$
\left(x_{i}^{e}\left(\hat{\mathbf{u}}_{i}\left(s_{i}^{\prime}\right), s_{i}, \hat{\mathbf{u}}_{-i}\right), u\left(x_{i}^{e}\left(\hat{\mathbf{u}}_{i}\left(s_{i}^{\prime}\right), s_{i}, \hat{\mathbf{u}}_{-i}\right)\right)-\hat{\mathbf{u}}_{i}\left(s_{i}^{\prime}\right)\right)
$$

with probability $1-\tau_{i}$ and a correct jointly ex-post efficient contract

$$
\left(x_{i}^{*}\left(s_{i}, s_{-i}\right), u\left(x_{i}^{*}\left(s_{i}, s_{-i}\right)-\hat{\mathbf{u}}_{i}\left(s_{i}^{\prime}\right)\right)\right.
$$

at each $s_{-i}$ with probability $\tau_{i}$, knowing that seller $i$ 's true signal is $s_{i}$. Therefore, the inequality in (26) holds. have

Because $\left\{\left(\hat{\mathbf{u}}_{1}, \hat{\mathbf{x}}_{1}\right), \ldots,\left(\hat{\mathbf{u}}_{N}, \hat{\mathbf{x}}_{N}\right)\right\}$ is a monotone equilibrium in the modified auction, we

$$
V_{i}\left(\hat{\mathbf{u}}_{i}\left(s_{i}^{\prime}\right), x_{i}^{e}\left(\hat{\mathbf{u}}_{i}\left(s_{i}^{\prime}\right), s_{i}, \hat{\mathbf{u}}_{-i}\right), \hat{\mathbf{u}}_{-i} \mid s_{i}\right) \leq V_{i}\left(\hat{\mathbf{u}}_{i}\left(s_{i}\right), \hat{\mathbf{x}}_{i}\left(s_{i}\right), \hat{\mathbf{u}}_{-i} \mid s_{i}\right)
$$

for a.e. $s_{i}$. Because $V_{i}\left(\mathbf{m}_{i}^{\tau}\left(s_{i}^{\prime}\right), \mathbf{m}_{-i}^{\tau} \mid s_{i}, \sigma_{i}^{\tau}\right) \leq V_{i}\left(\hat{\mathbf{u}}_{i}\left(s_{i}^{\prime}\right), x_{i}^{e}\left(\hat{\mathbf{u}}_{i}\left(s_{i}^{\prime}\right), s_{i}, \hat{\mathbf{u}}_{-i}\right), \hat{\mathbf{u}}_{-i} \mid s_{i}\right)$ by (26) and $V_{i}\left(\mathbf{m}_{i}^{\tau}\left(s_{i}\right), \mathbf{m}_{-i}^{\tau} \mid s_{i}, \sigma_{i}^{\tau}\right)=V_{i}\left(\hat{\mathbf{u}}_{i}\left(s_{i}\right), \hat{\mathbf{x}}_{i}\left(s_{i}\right), \hat{\mathbf{u}}_{-i} \mid s_{i}\right)$ by $(24),(27)$ implies, for a.e. $s_{i}$,

$$
V_{i}\left(\mathbf{m}_{i}^{\tau}\left(s_{i}^{\prime}\right), \mathbf{m}_{-i}^{\tau} \mid s_{i}, \sigma_{i}^{\tau}\right) \leq V_{i}\left(\mathbf{m}_{i}^{\tau}\left(s_{i}\right), \mathbf{m}_{-i}^{\tau} \mid s_{i}, \sigma_{i}^{\tau}\right) .
$$

Therefore, it is not profitable for seller $i$ with a.e. $s_{i}$ to deviate to $\mathbf{m}_{i}^{\tau}\left(s_{i}^{\prime}\right)$ with $s_{i}^{\prime} \neq s_{i}$ in the the first-price menu auction. 
Secondly, suppose that seller $i$ with an arbitrary signal $s_{i}$ deviates to a menu $m_{i} \neq \mathbf{m}_{i}^{\tau}\left(s_{i}^{\prime}\right)$ for all $s_{i}^{\prime} \in[0,1]$. In continuation equilibrium $\sigma^{\tau}$, the buyer takes characteristics $x_{i}$ along with the monetary payment $u\left(x_{i}\right)-\tilde{u}_{i}\left(m_{i}\right)$ with probability one upon accepting $m_{i}$. Suppose that seller $i$ deviates to submit $\left(\tilde{u}_{i}\left(m_{i}\right), x_{i}\right)$ in the modified auction. The winning event for seller $i$ in the modified auction is the same as the one in the the first-price menu auction. While the buyer always chooses $\left(x_{i}, u\left(x_{i}\right)-\tilde{u}_{i}\left(m_{i}\right)\right)$ in the the first-price menu auction upon accepting $m_{i}$, she chooses $\left(x_{i}^{*}(s), u\left(x_{i}^{*}(s)\right)-\tilde{u}_{i}\left(m_{i}\right)\right)$ with probability $\tau_{i}$ and $\left(x_{i}, u\left(x_{i}\right)-\tilde{u}_{i}\left(m_{i}\right)\right)$ with probability $1-\tau_{i}$ in the modified auction. Because $x_{i}^{*}(s)$ is jointly ex-post efficient, seller $i$ 's interim payoff upon deviation to a menu $m_{i}$ in the the first-price menu auction is no greater than the one associated with the deviation to $\left(\tilde{u}_{i}\left(m_{i}\right), x_{i}\right)$ in the modified auction. Therefore, we have

$$
V_{i}\left(m_{i}, \mathbf{m}_{-i}^{\tau} \mid s_{i}, \sigma_{i}^{\tau}\right) \leq V_{i}\left(\tilde{u}_{i}\left(m_{i}\right), x_{i}, \hat{\mathbf{u}}_{-i} \mid s_{i}\right) .
$$

Because $\left\{\left(\hat{\mathbf{u}}_{1}, \hat{\mathbf{x}}_{1}\right), \ldots,\left(\hat{\mathbf{u}}_{N}, \hat{\mathbf{x}}_{N}\right)\right\}$ is a monotone equilibrium in the modified auction, we have

$$
V_{i}\left(\tilde{u}_{i}\left(m_{i}\right), x_{i}, \hat{\mathbf{u}}_{-i} \mid s_{i}\right) \leq V_{i}\left(\hat{\mathbf{u}}_{i}\left(s_{i}\right), \hat{\mathbf{x}}_{i}\left(s_{i}\right), \hat{\mathbf{u}}_{-i} \mid s_{i}\right) .
$$

for a.e. $s_{i}$. From $(24),(28)$ and (29), we can conclude, for a.e., $s_{i}$,

$$
V_{i}\left(m_{i}, \mathbf{m}_{-i}^{\tau} \mid s_{i}, \sigma_{i}^{\tau}\right) \leq V_{i}\left(\mathbf{m}_{i}^{\tau}\left(s_{i}\right), \mathbf{m}_{-i}^{\tau} \mid s_{i}, \sigma_{i}^{\tau}\right) .
$$

Therefore, it is also not profitable for seller $i$ with a.e. $s_{i}$ deviates to a menu $m_{i} \neq \mathbf{m}_{i}^{\tau}\left(s_{i}^{\prime}\right)$ for all $s_{i}^{\prime} \in[0,1]$.

Because there is no profitable deviation for each seller $i$ in the the first-price menu auction, the existence of the separating monotone equilibrium $\left\{\mathbf{m}_{1}^{\tau}, \ldots, \mathbf{m}_{N}^{\tau}, \sigma^{\tau}\right\}$ follows immediately from the existence of the corresponding monotone equilibrium $\left\{\left(\hat{\mathbf{u}}_{1}, \hat{\mathbf{x}}_{1}\right), \ldots,\left(\hat{\mathbf{u}}_{N}, \hat{\mathbf{x}}_{N}\right)\right\}$ in the modified auction.

Proof of Proposition 1. If the buyer chooses a jointly interim efficient contract with positive probability $1-\tau_{i}$ from the winning seller $i, \tau_{i}<1$, then the ex-post surplus $R_{i}\left(\hat{\mathbf{x}}_{i}\left(s_{i}\right), s_{i}, s_{-i}\right)$ between the winning seller $i$ and the buyer is strictly less than the jointly ex-post efficient surplus for all $s_{i} \in Z_{i}$ and all $s_{-i} \in Z_{-i}$. It implies that with positive probability, the winning seller $i$ and the buyer can renegotiate in such a way that both of them are strictly better off by agreeing on a jointly ex-post efficient contract. When a separating monotone equilibrium $\left\{\mathbf{m}_{1}^{\tau}, \ldots, \mathbf{m}_{N}^{\tau}, \sigma^{\tau}\right\}$ is jointly ex-post efficient (i.e., $\tau_{i}=1$ for all $i$ ), one cannot find an alternative contract on which the buyer and the winning seller can mutually agree at any realized signal vector given the payoffs that they would receive from the buyer's original choice of a contract from the menu. It implies that only the jointly ex-post efficient equilibrium, i.e., $\left\{\mathbf{m}_{1}^{\tau}, \ldots, \mathbf{m}_{N}^{\tau}, \sigma^{\tau}\right\}$ with $\tau_{i}=1$ for all $i$, is jointly ex-post renegotiation-proof.

Proof of Theorem 3. Consider the separating monotone equilibrium $\left\{\mathbf{m}_{1}^{1}, \ldots, \mathbf{m}_{N}^{1}, \sigma^{\mathbf{1}}\right\}$ with $\mathbf{1}=[1,1, \ldots, 1]$. Note that it corresponds to a monotone equilibrium $\left\{\left(\hat{\mathbf{u}}_{1}, \hat{\mathbf{x}}_{1}\right), \ldots,\left(\hat{\mathbf{u}}_{N}\right.\right.$, $\left.\left.\hat{\mathbf{x}}_{N}\right)\right\}$ in the modified auction with $\tau_{i}=1$ for all $i$. Suppose that seller $i$ with signal $s_{i}$ deviates to an arbitrary menu $m_{i}$ that can induce the maximum payoff $u_{i}$ to the buyer in the first-price menu auction. When seller $i$ deviates to the payoff bid $u_{i}$ along with an action bid $x_{i}$ in the modified auction, his interim payoff upon such a deviation satisfies

$$
V_{i}\left(\hat{\mathbf{u}}_{i}\left(s_{i}\right), \hat{\mathbf{x}}_{i}\left(s_{i}\right), \hat{\mathbf{u}}_{-i} \mid s_{i}\right) \geq V_{i}\left(u_{i}, x_{i}, \hat{\mathbf{u}}_{-i} \mid s_{i}\right)
$$

for a.e. $s_{i}$ because $\left(\hat{\mathbf{u}}_{i}(\cdot), \hat{\mathbf{x}}_{i}(\cdot)\right)$ is bidder $i$ 's equilibrium strategy. Note that the buyer always chooses a jointly ex-post efficient contract in the modified auction and that the winning event 
for seller $i$ is the same whether he deviates to $m_{i}$ in the first-price menu auction or to the corresponding payoff bid $u_{i}$ along with an action bid $x_{i}$ in the modified auction. Therefore, we have that, for any continuation equilibrium $\sigma^{\prime}=\left[\sigma_{1}^{\prime}, \ldots, \sigma_{N}^{\prime}\right]$ and all $m_{i}$,

$$
V_{i}\left(u_{i}, x_{i}, \hat{\mathbf{u}}_{-i} \mid s_{i}\right) \geq V_{i}\left(m_{i}, \mathbf{m}_{-i}^{1} \mid s_{i}, \sigma_{i}^{\prime}\right) \text {. }
$$

Because

$$
V_{i}\left(\mathbf{m}_{i}^{\mathbf{1}}\left(s_{i}\right), \mathbf{m}_{-i}^{\mathbf{1}} \mid s_{i}, \sigma_{i}^{\mathbf{1}}\right)=V_{i}\left(\hat{\mathbf{u}}_{i}\left(s_{i}\right), \hat{\mathbf{x}}_{i}\left(s_{i}\right), \hat{\mathbf{u}}_{-i} \mid s_{i}\right),
$$

(30) and (31) imply that, for a.e. $s_{i}$,

$$
V_{i}\left(\mathbf{m}_{i}^{\mathbf{1}}\left(s_{i}\right), \mathbf{m}_{-i}^{\mathbf{1}} \mid s_{i}, \sigma_{i}^{\mathbf{1}}\right) \geq V_{i}\left(m_{i}, \mathbf{m}_{-i}^{\mathbf{1}} \mid s_{i}, \sigma_{i}^{\prime}\right)
$$

given any continuation equilibrium $\sigma^{\prime}=\left[\sigma_{1}^{\prime}, \ldots, \sigma_{N}^{\prime}\right]$ and all $m_{i}$. Therefore, the separating monotone equilibrium $\left\{\mathbf{m}_{1}^{\tau}, \ldots, \mathbf{m}_{N}^{\tau}, \sigma^{\tau}\right\}$ is ex-ante robust to every continuation equilibrium if $\tau=[1, \ldots, 1]$

\section{References}

[1] Asker, J. And E. Cantillon (2008), "Properties of Scoring Auctions," RAND Journal of Economics, 39 (1), 69 - 85.

[2] Athey, S. (2001), "Single Crossing Properties and the Existence of Pure Strategy Equilibria in Games of Incomplete Information," Econometrica, 69 (4), $861-889$.

[3] Bernheim, D. B. And M. B. Whinston (1986), "Menu Auctions, Resource Allocations and Economic Influence," Quarterly Journal of Economics, 101 (1), 1-31.

[4] Branco, F. (1997), "The Design of Multidimensional Auctions," RAND Journal of Economics, 28(1), 63-81.

[5] Bresky, M. (1999), "Equilibrium in Multi-Unit Auctions," Mimeo, CERGE-EI, Prague.

[6] Che, Y.-K. (1993), "Design Competition through Multidimensional Auctions," RAND Journal of Economics, 24 (4), 668-680.

[7] Dasgupta, P. And E. Maskin (2000): "Efficient Auctions," Quarterly Journal of Economics, 115 (2), 341-388.

[8] Han, S. (2007) "Strongly Robust Equilibrium and Competing-Mechanism Games," Journal of Economic Theory, 137, 610-626.

[9] Jackson, M., AND J. Swinkels (2005), "Existence of Equilibrium in Single and Double Private Value Auctions," Econometrica, 73 (1), 93 - 140. 
[10] KirkegaARD, R. (2012), "A Mechanism Design Approach to Ranking Asymmetric Auctions," Econometrica, 80 (5), 2349-2364.

[11] Lebrun, B. (1999), "First-Price Auctions in the Asymmetric N seller Case," International Economic Review, 40 (1), 125-142.

[12] Maskin, E. And J. Riley (2000a), "Equilibrium in Sealed High-Bid Auctions," Review of Economic Studies, 67 (3), 439-454.

[13] - (2000b), "Asymmetric Auctions," Review of Economic Studies, 67, 413-438

[14] McAdams, D. (2006), "Monotone Equilibrium in Multi-Unit Auctions", Review of Economic Studies, 73 (4), 1039-1056.

[15] Milgrom, P. R. And C. Shannon (1994), "Monotone Comparative Statics," Econometrica, 62 (1), 157-180.

[16] Milgrom, P.. R. And R. J. Weber (1982), "A Theory of Auctions and Competitive Bidding," Econometrica, 50 (5), 1089-1122.

[17] Reny, P. J. (2011), "On the Existence of Monotone Pure Strategy Equilibria in Bayesian Games," Econometrica, 79 (2), 499-553.

[18] Reny, P. J. And S. Zamir (2004), "On the Existence of Pure Strategy Monotone Equilibria in Asymmetric First-Price Auctions," Econometrica, $72(4), 1105-1125$. 